\title{
A CONCISE GUIDE TO MARL C-POTTERY*
}

Von Bettina Bader

Until recently Marl C has, with one notable exception, ${ }^{1}$ been neglected in the wide range of pottery research and it is hoped that this article will highlight the importance and significance of this fabric both to the ancient Egyptians and to modern researchers. The reason why this fabric in particular should be looked at more closely lies both in its distinctiveness and in the corpus of forms, some of which appear only rarely in other fabrics. If we can establish when certain types of Marl C vessels appear or disappear in certain levels and compare these ocurrences on different sites, we could relate the chronology of the sites more easily to each other. Further research is absolutely necessary as there are many "blank spots" on the Egyptian map where we do not know if Marl C appears or not, especially in Middle Egypt. For this area we have to rely almost exclusively on old excavation memoirs as hardly any new work has been conducted there recently. Because of these gaps the regional distribution of Marl C is still not fully understood and prevents us from possibly pinpointing the whereabouts of the original raw source of the Marl C-clay.

The description of the fabric Marl C is only sum-

\footnotetext{
* I would like to thank M. Bietak director of the Austrian Excavations at Tell el-Dabca, together with J. Bourriau and the Egypt Exploration Society's expedition to Memphis for their permission to refer to material that is mentioned in this paper. I am particularly thankful to Susan Allen for her most extensive comments on a draft of this paper. I would also like to thank Susan Allen and David Aston for the correction of my treatment of the English language. As this paper should serve as an English summary, not all the pieces I will refer to will be shown in drawing and with complete description, but only the most common types. For a more thorough treatment cf. B. BADER, Tell el-Dabc $a$ XIII, Typologie und Chronologie der Mergel C-Ton Keramik, Vienna 2001 (in the following quoted as B. BADER, TD XIII). Note that only a small part of the Marl C-material from Kom

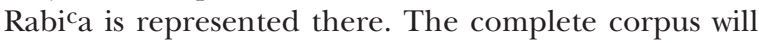
be published by J. Bourriau.

1 Do. Arnold, Ägyptische Mergeltone („Wüstentone“) und die Herkunft einer Mergeltonware des Mittleren Reiches aus der Gegend von Memphis, in: Do. ARNOLD (ed.), Studien zur altägyptischen Keramik, Mainz 1981,
}

marized briefly below, as it has already been described and divided into three subgroups: ${ }^{2}$ Marl C compact, Marl C 1 and Marl C 2. These terms are now generally used in most publications. At the site of Tell el-Dabca in the Eastern Nile Delta this terminology is equal to II-c-1, II-c-2 and II-c-3, respectively. Among the Marl C 1 examples available for visual analysis, most of which came from Tell el-Dabca, were some which showed a much finer distribution and sorting of the inclusions (see below), but not the density of Marl C compact. I have previously termed this latter variant Marl C 1 , fine. ${ }^{3}$

The main distinction between the three subgroups is density (Marl C compact) and the presence of limestone and quartz grains, respectively. In Marl C 1 the limestone particles ${ }^{4}$ predominate giving the fabric its distinctive speckled appearance, whereas in C 2 the quartz grains are more numerous. ${ }^{5}$ Other inclusions are: reddish-brown particles of unmixed clay or marl (German: Tonstein), tiny black rock particles and small amounts of white mica as well as other inclusions which occur more rarely and which cannot be identified without further petrographic analysis. ${ }^{6}$

Another distinctive feature of many kinds of

167-91 (in the following quoted as Do. ARnOLD, Wüstentone).

2 H.-Å. Nordström, J. Bourriau, Ceramic Technology: Clays and Fabrics, in: Do. ARNold, (ed.), Introduction to Ancient Egyptian Pottery, Mainz 1993, 179-81 (in the following quoted as Nordström, Bourriau, Clays and Fabrics).

3 Photos of all variants are to be found in B. BADER, TD XIII, colour plates I-V.

4 To date it is not clear whether these so-called particles were intentionally added or already present in the raw clay.

${ }^{5}$ At Tell el-Dabca there exists a distinctive, extremely sandy variant of this fabric, which is in texture and "ingredients" very similar to Marl F, and seems to have a particular distribution pattern. Cf. M. BIETAK, Tell el$D a b^{c} a$ V, Vienna 1991, 328. K. Kopetzky, The Fabrics of Tell el-Dabc $a$ and Their Chronological Distribution, Lecture held at Haindorf Conference 2001.

${ }^{6}$ A detailed description of all inclusions, which occur has been attempted in B. BADER, TD XIII, Vienna 2001, 24-9, but geological and petrographic research in this field is sorely needed. 
marl clay is the whitish surface on the outside of fired vessels, which is also sometimes called a self slip. ${ }^{7}$ In the case of Marl C it is usually, but not always, very marked in contrast to the red/reddish-brown colour of the break. The white surface has been differently called "scum", self slip" or even "white slip". Several tests and observations have, however, shown that the white surface colour derives from the presence of soluble salts in the clay and develops either in the course of drying or firing in the kiln. Therefore I would prefer to call this feature simply the natural surface colour. ${ }^{8}$ There have, however, been cases where insufficient white surface colour has been "beautified" with what looks like a real white slip. The distinction is certainly tricky, but thick white drips or broken thick layers of a white paste like "Belag" are perhaps an indicator of a deliberately applied slip. The reason why the white surface colour was sometimes not well developed, has not yet been discovered. BOURRIAU presumed that when more quartz than usual was present in the paste, the white surface is not formed. ${ }^{9}$

The time range in which Marl C appears is somewhat longer than hitherto thought. Well known from the later Middle Kingdom and Second Intermediate

7 The term "self slip" is used here in the following sense: a white layer on the surface of the vessel developed by itself in the course of production through the presence of soluble salts. But it does not mean a slip consisting of the same material as the vessel. Cf. BADER, TD XIII, 22 , footnote 54 . The white surface can also be used as an indicator whether a given sherd belonged to an open or closed vessel, because on closed vessels only the outside shows this surface colour whereas on open shapes the inside is also white. There are, of course, exceptions, that could be explained by placing vessels inside each other in the kiln or while drying.

8 F. R. MATSOn, Technological Studies of Egyptian Pottery Modern and Ancient, in: A. BISHAY (ed.), Collected Papers of the $2^{\text {nd }}$ Cairo Solid State Conference, 1973, Recent Advances in Technology of Materials, New York, San Francisco, London 1974, 136-138. Cf. Do. ARnold, The Pottery, in: D. ARNOLD, The Pyramid of Senwosret I, The South Cemeteries of Lisht, Vol. I., The Metropolitan Museum of Art Expedition, Vol. XXII., New York 1988, 126 (in the following quoted as Do. Arnold, Senwosret I). H. J. Franken and G. LONDON, Why Painted Pottery Disappeared at the End of the Second Millennium BCE, BA 58 (1995), 217 give a description of how such a surface develops.

9 J. BOURRIAU, pers. comm.

10 According to B. Crouwell (Giza) and D. Faltings (Dahshur) mentioned in Nordström, Bourriau, Clays and Fabrics, 180, already in the $4^{\text {th }}$ Dynasty. Additionally D. Raue found pottery made from Marl C in OK material in Dahshur, personal comm.
Period its presence, has now been identified in Old Kingdom deposits at Giza and Dahshur, ${ }^{10}$ and is known in early $12^{\text {th }}$ Dynasty levels at Tell el-Dabc $\mathrm{a}^{11}$ and the pyramid temple of Lisht South. ${ }^{12}$ Similarly, there is increasing evidence for Marl $\mathrm{C}$ in part of the First Intermediate Period in Northern Egypt. ${ }^{13}$ The chronological gaps may be explained by several possibilities: $a$ ) the location of the raw sources of the clay had been forgotten, $b$ ) the political situation allowed no access to them, $c$ ) the administration at that time was not centralised enough in order to exploit and distribute the raw clay or vessels on a large scale, and d) not enough sites with FIP pottery in them have been dug in order to be sure (which is my preference). ${ }^{14}$ For the $11^{\text {th }}$ Dynasty Southern Egypt provides ambiguous evidence as no Marl $\mathrm{C}$ vessels were found at Tarif, ${ }^{15}$ but further south at Elephantine there are examples. The fabric continued to be used to at least the early New Kingdom. Based on current evidence the frequency of vessels in this fabric is highest in the Middle Kingdom and the Second Intermediate Period. At Kom Rabica it is still present in levels that date to the beginning of the $18^{\text {th }}$ Dynasty, but the percentage drops considerably. ${ }^{16}$ After this time it becomes rare. Still, we have a patchy

11 At Tell el-Dabca Marl C has been found as early as the beginning of the $12^{\text {th }}$ Dynasty. cf. E. Czerny, Eine Siedlung des Mittleren Reiches, Tell el-Dabca IX, Vienna 1999.

12 Do. Arnold, Senwosret I, passim.

13 The appearance of Marl C at Sedment could be proved by checking vessels from cemetery $\mathrm{N}$, which are presently housed in the Petrie Museum in London, by courtesy of Petrie Museum and its previous curator B. Adams ( $\dagger$ ). This cemetery has been variously dated to the FIP and MK. According to Do. ARnold, Senwosret I, 144-145, who looked at these vessels, they date to the early MK. Personal observation of one vessel of type $90 \mathrm{r}$, from Cemetery G, shows it to have been made of Marl C. As Cemetery $G$ is dated to the $9^{\text {th }}-11^{\text {th }}$ Dynasties, the early appearance is further corroborated.

14 The Spanish excavation at Herakleopolis Magna under C. PÉrez-Die showed that in presumed FIP levels an increasing number of Marl C vessels were found. More data will hopefully be available soon so that this question can be at least partly answered.

15 Do. Arnold, Wüstentone, 190; Eadem, Weiteres zur Keramik von el-Tarif, MDAIK 28,1 (1972), 33-46; Eadem, Keramikbeispiele aus den Gräbern der frühen 11. Dynastie, MDAIK 23 (1968), 38-67.

16 J. Bourriau, K. O. Eriksson, A Late Minoan Sherd from an Early $18^{\text {th }}$ Dynasty Context at Kom Rabica, Memphis, in: J. Phillips (ed.), Ancient Egypt, the Aegean and the Near East. Studies in Honour of Martha Rhoads Bell, San Antonio 1998, 95-120. 
record for some regions of Egypt, and so regional preferences should be treated with caution.

In her 1981 article Do. Arnold ${ }^{17}$ proposed that the original centre of production of Marl $\mathrm{C}$ was the Memphis-Fayoum region, just south of the modern capital Cairo. She based this conclusion on a thorough study of the Marl C finds in Egypt then known from the sites of Lisht, ${ }^{18}$ Illahun, ${ }^{19}$ Dahshur, ${ }^{20}$ Qasr elSagha, ${ }^{21}$ Harageh, ${ }^{22}$ Kahun, ${ }^{23}$ Riqqeh,${ }^{24}$ Safaga near the Red Sea and Buhen. ${ }^{25}$ We now can add material from Tell el-Dabca, ${ }^{26}$ Tell Ibrahim Awad, ${ }^{27}$ Abu Ghâlib, ${ }^{28}$ (Tell el-Maskhuta), ${ }^{29}$ the Northern Sinai, ${ }^{30}$

17 Do. ARNOLD, Wüstentone, 188-90.

18 A. LAnsing, The Egyptian Expedition, 1931-2, The Museum's Excavations at Lisht, BMMA 28, April 1933, 14, fig. 12. See also Do. ARnold, Senwosret I, 112.

19 W. M. F. Petrie, Kahun, Gurob and Hawara, London 1890, pl. 14, Nr. 16-7. C. Gallorini analysed two pots from the foundation deposit of the Mortuary Temple of Senwosret II at Lahun in the Museum of Manchester and proved that they are made of Marl C fabric. C. Gallorini, personal comm.

20 Do. ARnOld, Zur Keramik aus dem Taltempelbereich der Pyramide Amenemhets III. in Dahschur, MDIK 33 (1977), 21-6. Eadem, Keramikbearbeitung in Dahschur 1976-1981, MDIK 38 (1982), 25-65. J. DE MORGAN, Fouilles à Dahchour, Mars-Juin 1894, Vienne 1895, 74, figs. 164-5.

21 D. and Do. Arnold, Der Tempel von Qasr el-Sagha, AV 27, Mainz 1979, 29-40.

22 R. Engelbach, B. Gunn, Harageh, London 1923, Taf. XXXIV-XLI; B. J. Kemp, R. S. MerrilleEs, Minoan Pottery in Second Millennium Egypt, Mainz 1980, 22 "distinct white surfaced fabric".

23 Do. ArNold, Wüstentone, 189.

24 R. ENGELBACH, Riqqeh and Memphis VI, London 1915.

25 Do. Arnold, Wüstentone, 190. For Buhen see W. B. Emery, H. S. Smith, A. Millard, The Fortress of Buhen. The Archaeological Report, EES, London 1979.

${ }^{26}$ M. BieTaK, Tell el-Dabc $a$ V, Vienna 1991, passim.

27 Identified at a visit at the site, by courtesy of W. v. Haarlem.

28 T. BAGH, Abu Ghâlib, An Early Middle Kingdom Town in the Western Nile Delta: Renewed Work on Material Excavated in the 1930s, MDAIK 58 (2002), 39, $58-61$.

29 C. A. Redmount, On an Egyptian/Asiatic Frontier: An Archaeological History of the Wadi Tumilat, Vol. I-IV, unpublished Ph.D. Thesis, Chicago 1989, 326-8; C. A. Redmount, Ethnicity, Pottery and the Hyksos at Tell elMaskhuta in the Egyptian Delta, Biblical Archaeologist 58:4 (1995), 185. This is still not proved, as the Vienna System was not used as concordance and the present writer had no chance to see the material.

30 E. OREn, The "Kingdom of Sharuhen" and the Hyksos Kingdom, in: E. Oren (ed.), The Hyksos: New Historical
Serabit el-Khadim, ${ }^{31}$ Kom Rabica ${ }^{32}$ Herakleopolis Magna, ${ }^{33}$ Wadi Gawasis, ${ }^{34}$ Karnak-North, ${ }^{35}$ Elephantine ${ }^{36}$ and Askut. ${ }^{37}$ Whilst it is thus reasonable to think that the main source of Marl C pottery for the Delta and Middle Egypt was, in fact, in the Memphis-Fayoum area, ${ }^{38}$ the possibility that there was at least one more source for the south, namely for Karnak and Elephantine, cannot yet be discounted. ${ }^{39}$ The fact that a well-known type - usually made of Marl C appeared in Abydos made from Marl A4, beside other types made from Marl C, ${ }^{40}$ shows that there are many more possibilities for research in the future. and Archaeological Perspectives, Phildadelphia 1997, 273-9, fig. 8.23 with subtitles from 8.24. Pottery from the Northern Sinai has been identified as Marl C by M. Bietak, personal comm.

${ }^{31}$ J. BourRIAU, Observations on the Pottery from Serabit el-Khadim (Zone Sud), CRIPEL 18 (1996), 19-32.

${ }^{32}$ J. BourriaU, Kom Rabica, BCE XI (1986), 22-3, XII (1987), 10-1; XIII (1988), 29-31. Joint work made it possible to see the Marl C ceramics there.

33 M.-C. Pérez-Die, personal comm. The fabric has been identified by the writer.

${ }^{34}$ Seen by M. Bietak, personal comm.

35 H. JaQuet-Gordon, Karnak-Nord, 1989, BCE XV (1991), 27-9. These „Zeirs“ are made from marl clay "avec beaucoup d' inclusions". They are dated to the Middle Kingdom. Unfortunately none of these pots is published in greater detail, but in NORDSTRÖM, BOURRIAU, Clays and Fabrics, 80 a personal communication is mentioned, that confirms the use of Marl C for these vessels.

36 „Ausgewählte Keramik“ has been published by C. v. PILGRIM, Elephantine XVIII, Untersuchungen in der Stadt des Mittleren Reiches und der Zweiten Zwischenzeit, AV 91, Mainz 1996. Among these are some Marl C pots.

37 S. T. SMITH, Askut in Nubia, The Economics and Ideology of Egyptian Imperialism in the Second Millennium B. C., London, New York 1995, figs. 3.6-3.7, 200.

38 The more so as J. Huntoon undertook some NAA testing of raw clay sources published in McGovern (three samples: Dahshur (1), Kahun (2)) in the Memphis-Fayoum region. He found they matched the vessels made from Marl C. P. MC Govern, The Foreign Relations of the Hyksos. A Neutron Activation Study of Middle Bronze Age Pottery from the Eastern Mediterranean, BAR IS 888, Oxford 2000, 27. The small number of three samples seems to be but a start of research and the results cannot be taken to prove the only raw clay source being in the Memphis-Fayoum region.

39 To my knowledge no relevant NAA or petrographic research on visually identified Marl C sherds has been done on material from Southern Egypt.

40 J. Wegner, V. SMith, S. Rossell, The Organization of the Temple $N f r-K 3$ of Senwosret III at Abydos, $\ddot{A} \mathcal{E} L 10$ (2000), figs., 9.32, 17.45. 


\section{The Corpus}

The Corpus given in this paper will not be as comprehensive as the most recent study of the topic. Only the common types will be repeated here in chronological order rather than in a typological system. ${ }^{41}$

\section{Phase A) First Intermediate Period to Early Middle Kingdom}

Open shapes

At present no open shapes are known from the First Intermediate Period, but plates and dishes of simple form in various sizes (types 1 and 2, see Fig. 1) occur from the very beginning of the $12^{\text {th }}$ Dynasty onwards. At this time, however, they are somewhat rare. $^{42}$

Presumably settlement pottery is represented by the carinated cups, type $12,{ }^{43}$ with flat, flattened ${ }^{44}$ or ring bases, which first appear during the early $12^{\text {th }}$ Dynasty $^{45}$ (Fig. 1). The rim diameter of this type varies considerably from around $12 \mathrm{~cm}$ to over 30 $\mathrm{cm}$, but the size does not seem to reflect a development over time. Other dateable examples were found in Dahshur complex 6 (late $12^{\text {th }} /$ early $13^{\text {th }}$ Dynasty) ${ }^{46}$ and complexes $5^{47}$ and $7^{48}$ (latter two thirds of $13^{\text {th }}$ Dynasty), at Kom Rabica/Memphis in levels of the later $13^{\text {th }}$ Dynasty ${ }^{49}$ and at Qasr el-Sagha in the later $13^{\text {th }}$ Dynasty. ${ }^{50}$ The form of the carinated cup was widespread all over Egypt in a variety of fabrics like Nile clay $^{51}$ and Upper Egyptian Marl A ${ }^{52}$ in the Middle Kingdom and the Second Intermediate Period.

Carinated bowls, type 13 (Fig. 1), known from Tell el-Dabca seems to be an early $12^{\text {th }}$ Dynasty type, that has largely no secure contemporary parallels elsewhere. $^{53}$
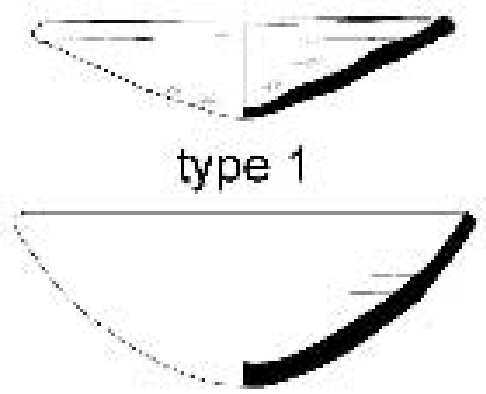

type 2

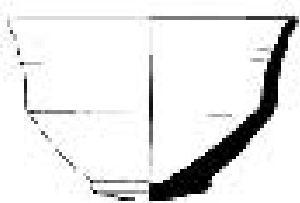

type 12

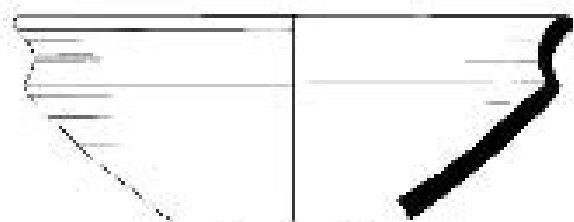

type 13

Fig. 1 Phase A, open shapes, scale 1:4

${ }^{41}$ B. BADER, TD XIII, passim. To avoid confusion the type numbers used here are the same as those employed there.

42 Do. Arnold, Senwosret I, 52-3, fig. 74/30. E. Czerny, TD IX, 185, Mc 1-28. In B. BADER, TD XIII, these shapes are represented by type numbers $1-2$.

43 B. BADER, TD XIII, 53-6.

${ }^{44}$ Like one complete example from Kom Rabica/RAT. J. Bourriau, personal comm.

45 E. Czerny, TD IX, 186, Mc 22-28. The shape already appears in the First Intermediate Period. Cf. W. M. F. Petrie, G. Brunton, Sedment I, BSAE 34, London 1924, pl. $29.30 \mathrm{f}$.

46 Do. Arnold, Keramikbearbeitung in Dahschur 1976-1981, MDAIK 38 1982), 47, fig. 8.4.
47 Do. ArNOLD, MDAIK 38, 40, fig. 11.2.

48 Do. Arnold, Zur Keramik aus dem Taltempelbereich der Pyramide Amenemhets III. in Dahschur, MDAIK 33 (1977), 25, fig. 1, II 1.

49 J. Bourriau, personal comm.: levels VII, VIe-b.

50 D. and Do. Arnold, Der Tempel von Qasr el-Sagha, AV 27, Mainz 1979, 34, fig., 20.1.

51 Examples: Czerny, TD IX, 142-147. J. E. Quibell, El Kab, London 1989, pl. 15. 13, 14, 16. W. M. F. Petrie, Kahun, Gurob and Hawara, pl. 12.4-7. More Comparanda in B. BADER, TD XIII, passim.

52 E. Czerny, TD IX, 184, Ma 2.

53 See discussion in B. BADER, TD XIII, 56-58. E. CzErny, TD IX, 186, Mc 9-21. 


\section{Closed shapes}

The relative scarcity of open shapes compared to closed shapes in this fabric can perhaps be explained by the primary use of this pottery for the transport of commodities, the nature of which still eludes us to its full extent. Some inscriptions and depictions give information on the use of some of these vessels (see below).

It seems as if amongst the plentiful jar types, ${ }^{54}$ common from the First Intermediate Period to the $11^{\text {th }}$ Dynasty, those with a very pointed base such as type 30 (Fig. 2), ${ }^{55}$ were preferably produced from marl clay. U.C. 18189 now in the Petrie Museum is made of Marl C. ${ }^{56}$ Close parallels for type 30, made of Marl C, can also be found at Herakleopolis Magna. ${ }^{57}$ Whether the variation in the material is a chronolog- ical or local development or rather an experimental specialisation of a type cannot be said at this moment in time, because too little data is available.

A variety of jars and jar rims made of Marl C appear from the time of Tell el-Dabca F/I-str. "e", which corresponds to the early $12^{\text {th }}$ Dynasty, ${ }^{58}$ among them type $28,{ }^{59}$ elongated jars with simple rims and $31,{ }^{60}$ ovoid jars with infolded rims (Fig. 2).

In the South, at Elephantine, in levels dated to the $11^{\text {th }}$ to $12^{\text {th }}$ Dynasties, we find at least one different kind of jar with elongated body, type $35^{61}$ (Fig. 2) that seems to be only remotely related to the northern types. ${ }^{62}$

Type 36a, medium-sized jars (Fig. 3), has a kind of precursor at Elephantine in levels dated to $11^{\text {th }}$ or early $12^{\text {th }}$ Dynasty (see below for details).$^{63}$

Large jars with funnel necks, type 44 (Fig. 3), only
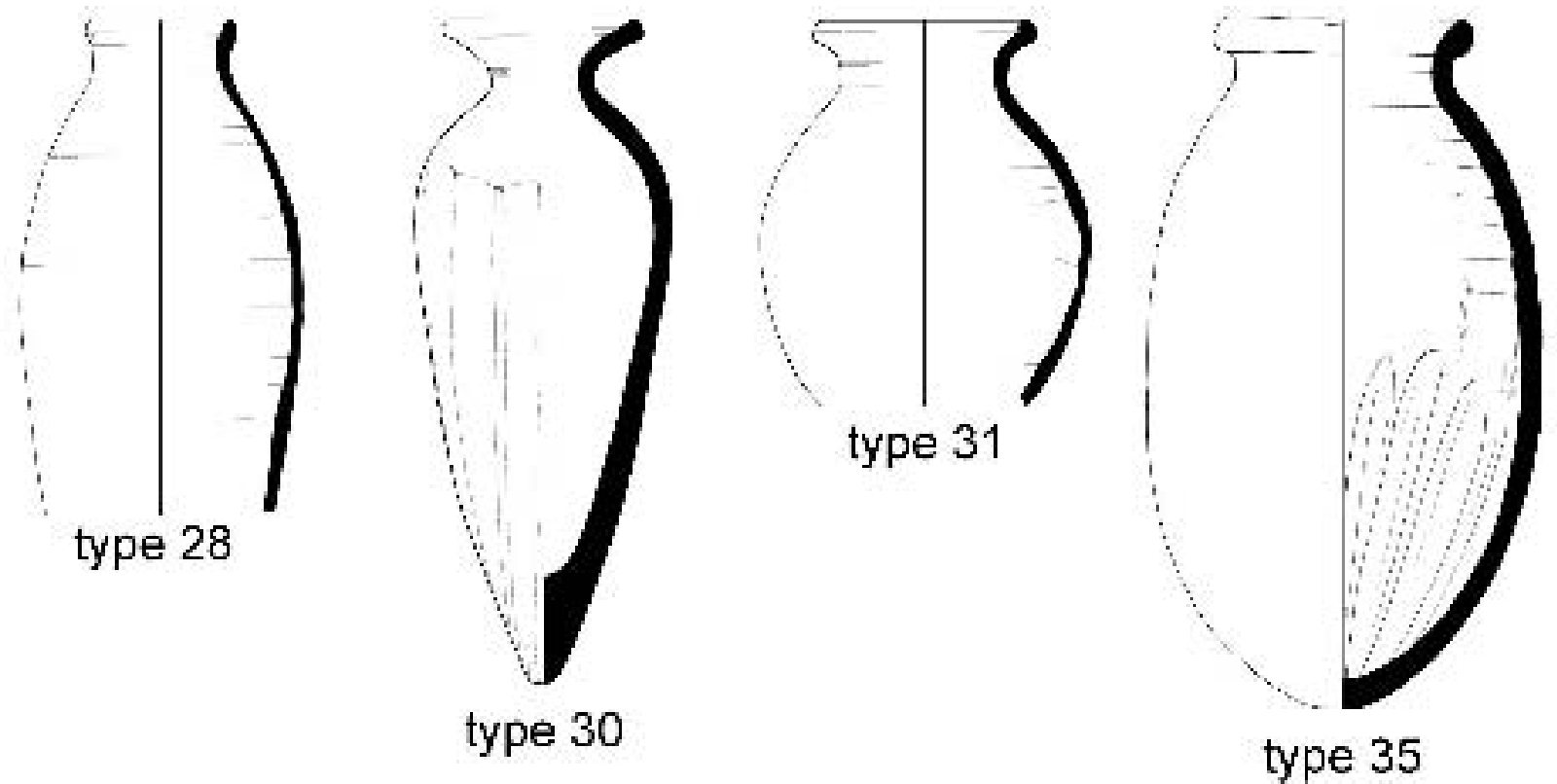

Fig. 2 Phase A, closed shapes, scale 1: 4

\footnotetext{
54 W. M. F. Petrie, G. Brunton, Sedment I, pls. 33-35, types 63-75, 85-90.

55 Corresponds to type 90 r. W. M. F. Petrie, G. Brunton, Sedment I, pl. 35 .

${ }^{56}$ B. BADER, TD XIII, fig. 21.e. Other members of vessel family 90 , that are housed in the Petrie Museum are also of marl clay. According to Do. ArNold, Senwosret I, 144, Cemetery G dates to the FIP.

57 Identified during a visit by kind permission of M. del Carmen Pérez-Die.

58 Types 28-31a and 44, B. BADER, TD XIII, 100-4, 125-7.
}

${ }^{59}$ Corresponds presumably to type $66 \mathrm{n}$ and consists of Marl C. W. M. F. Petrie, G. Brunton, Sedment I, pl. 33. Do. Arnold, Senwosret I, 144-5, footnote 342. See footnote 13. E. CZERnY, TD IX, 193, Mc 122.

${ }^{60}$ Corresponds perhaps to type $74 \mathrm{~m}$. W. M. F. PEtrie, G. BRunton, Sedment I, pl. 33. E. CZERny, TD IX, 194, Mc 122.

${ }^{61}$ C. v. PILGRIM, Elephantine XVIII, 360-1, fig. 161.d. B. BADER, TD XIII, 107-8, fig. 22.1.

${ }^{62}$ Cf. W. M. F. Petrie, G. Brunton, Sedment I, pl. 31. 52g, Cemetery G, VI 48.

${ }^{63}$ C. v. Pilgrim, Elephantine XVIII, 359, fig. 160 i. 
fragmentarily preserved, can be considered as ubiquitous form at Tell el-Dabca in the early Middle Kingdom (F/I - stratum "e"). ${ }^{64}$ They may be similar to the complete shapes from Toshka, ${ }^{65}$ Aniba $^{66}$ and Quban $^{67}$ from the Middle Kingdom. Other, betterdated comparanda are not known. It is possible that this type is a precursor of the later type 46 (see below) and does not continue into the later phases.

Type 47, large bag-shaped jars with corrugated necks
(Fig. 3), also occurs at Elephantine in levels of $11^{\text {th }}$ or early $12^{\text {th }}$ Dynasty date. This vessel type is related to the later egg-shaped jars with corrugated necks (type 46) and is either a precursor or an example of parallel development. Unfortunately complete vessels are rare, and the rims of types 46 and 47 are at the moment indistinguishable. A larger rim diameter and thicker vessel wall may be an indicator of type 47 rather than type 46 (Fig. 7) ${ }^{68}$

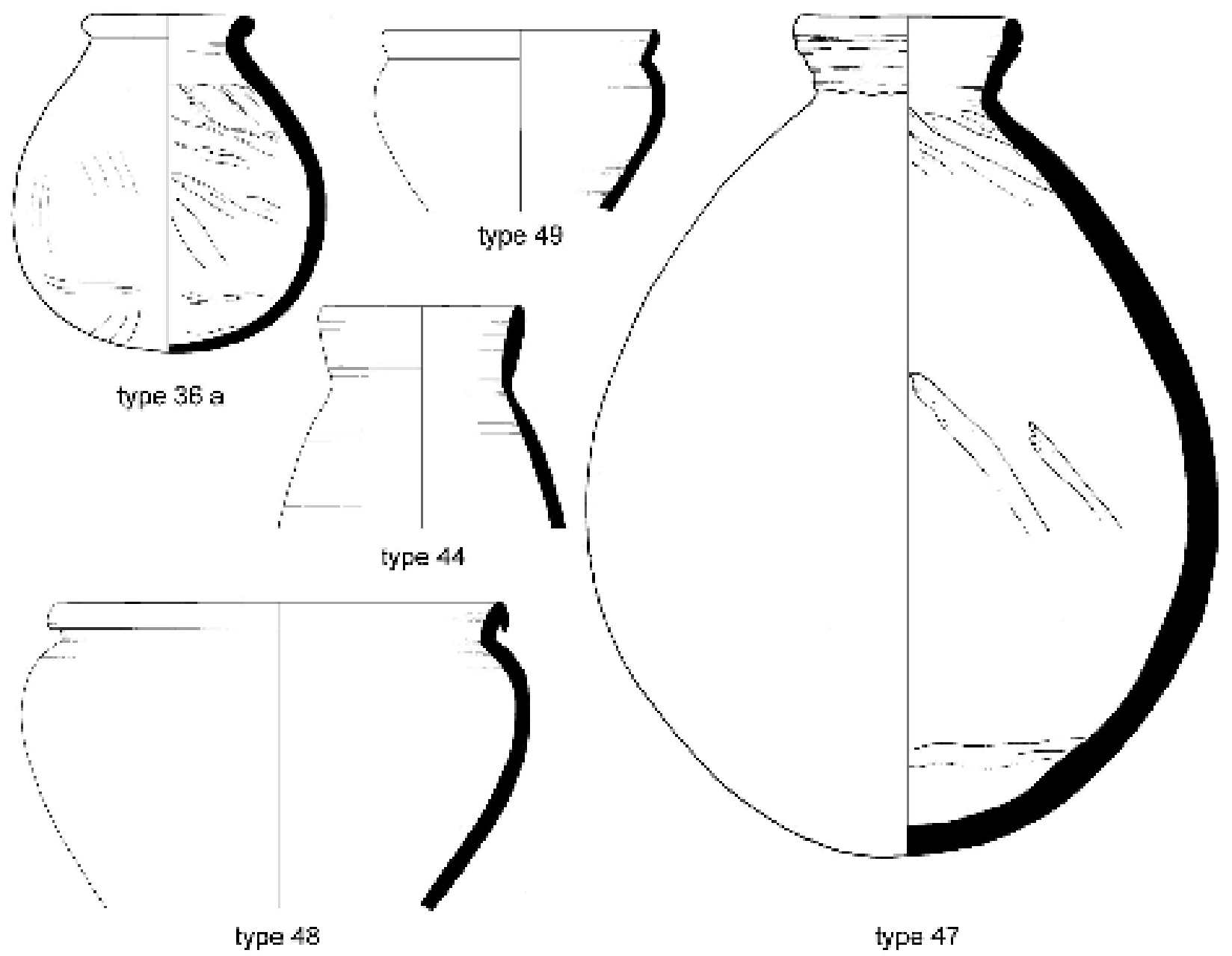

Fig. 3 Phase A, closed shapes, scale 1: 4

${ }^{64}$ B. BADER, TD XIII, 125-6, figs. 28.i-j, 29.a. E. CZERNY, TD IX, 95-8, 191-2, Mc 78-118; BAGH, MDAIK 58, fig. 9c.

65 H. Junker, Berichte über die Grabungen der Akademie der Wissenschaften in Wien auf dem Friedhof in Toschke (Nubien) im Winter 1911/1913. Wien/Leipzig 1926, Denkschr. 68. Bd., Abh. 1, 52-4, pl. XXII. 328-31, 333-4, 337.

${ }_{66}$ G. SteindorfF, Aniba, vol. 1, Glückstadt, Hamburg 1935, 98, 105-6, pl. 60.6.

67 W. B. Emery, L. P. KIRWAN, Excavations and Survey between Wadi el-Sebua and Adindan, Survey of Egypt, 1929-1931, Cairo 1935, pl. 34, type C. III.
68 C. v. PILgrim, Elephantine XVIII, 357, figs. 160.j, 161.c; T. Rzeuska, Stadt und Tempel von Elephantine, 25./26./27. Grabungsbericht, MDAIK 55 (1999), fig. 44.5. Additional evidence can be found at Kerma where an intermediary type in terms of body shape exists, made from Marl C. Cf. J. Bourriau, Relations between Egypt and Kerma During the Middle and New Kingdoms, in: W. V. Davies (ed.), Egypt and Africa, London 1991, 129, footnote 12, pl. 6.1. D. Dunham, Excavations at Kerma VI, MFA Boston 1982, passim. 
Another distinctive and seemingly exclusive type of the early Middle Kingdom is type 48, wide-bodied jars (Fig. 3). ${ }^{69}$ This type is so far only known through rim fragments, so that the complete shape can only be tentatively reconstructed with a flat base. The rim diameter ranges from 20 to $25 \mathrm{~cm}$ and exact parallels have not come to light to date. ${ }^{70}$

The somewhat rare type 49, small jars with everted rims (Fig. 3), shows similar features in terms of proportion to 48 , but is much smaller. The rim diameter is around 11 to $15 \mathrm{~cm}$; the reconstructed height about 12 to $15 \mathrm{~cm}$. That this type of vessel is typical only for the early Middle Kingdom is questionable, as a close parallel exists at Kom Rabica/ Memphis that dates to the advanced $13^{\text {th }}$ Dynasty. ${ }^{71}$
A frequently found and therefore important vessel type is 57a, the main storage jars (generally called Zeir after the Arabic word, Fig. 4) of the early Middle Kingdom. ${ }^{72}$ It is of crucial importance to note that "vessel family" 57 provides a long, chronologically significant development from the early Middle Kingdom to the beginning of the New Kingdom, which is not yet fully understood as not many complete vessels were found. The shape of the rims themselves also changes significantly over time. ${ }^{73}$ The rim diameter ranges between 25 and $40 \mathrm{~cm}$, while the body is usually bag-shaped, although sometimes nearly cylindrical. ${ }^{74}$ The height of these vessels measures around $60 \mathrm{~cm}$, but there are indications that several sizes existed. ${ }^{75}$ The occurrence of this type can be secure-

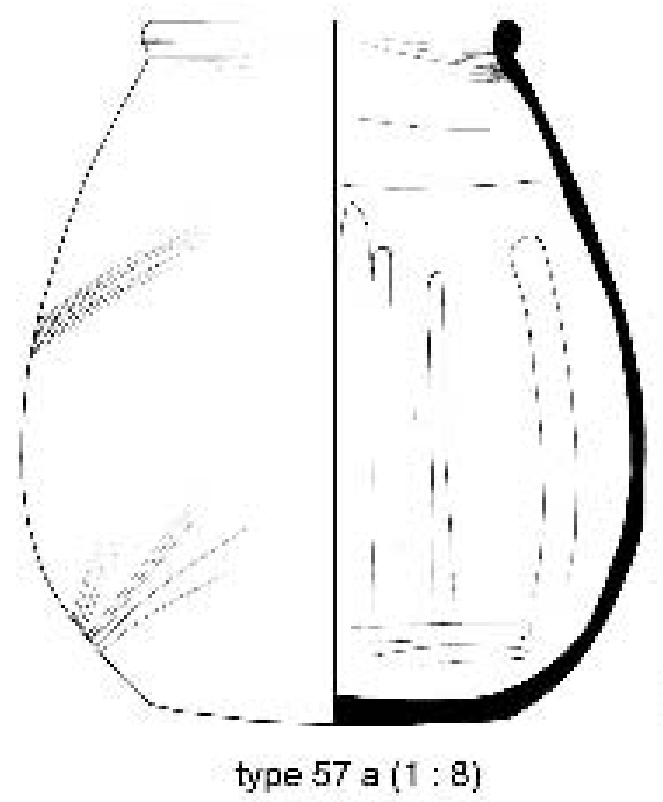

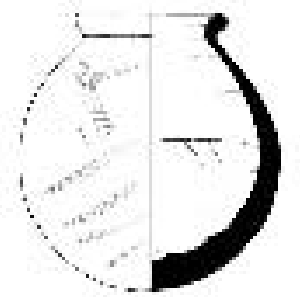

type 62

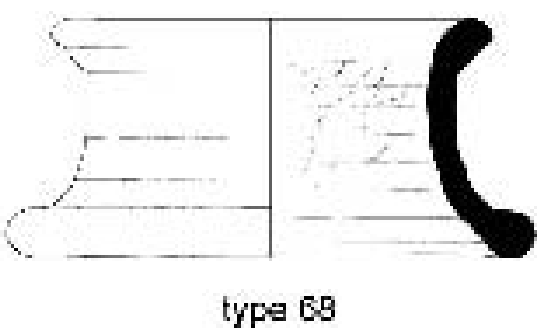

Fig. 4 Phase A, closed shapes and "non-containers", scale 1: 4

${ }^{69}$ B. BADER, TD XIII, 146-9, figs. 40.a-f. E. CZERnY, TD IX, 92-3, Mc 42-70, 187-8.

70 Except a rim fragment from Kom Rabica/Memphis: cf. B. BADER, TD XIII, fig. 40.d.

71 B. BADER, TD XIII, 149, fig. 41.b. Dating to level VIIc, J. Bourriau, pers. comm.

72 B. BADER, TD XIII, 155-60. It is perhaps feasible to think that this type may already have existed in the First Intermediate Period, because rim fragments of type 57 a have been found in Herakleopolis Magna in levels that are preliminarily dated to this period. Its early appearance is likely, because the type presumably developed some time before the beginning of the $12^{\text {th }}$ Dynasty as it occurs in find complexes that are dated to Sesostris I.

73 See the charts in B. BADER, TD XIII, figs. 42.f, 43.
${ }^{74}$ For both types cf. E. CZERnY, Zur Keramik von Ezbet Rushdi, $\ddot{A} \mathcal{E} L 8$ (1998), 45, fig. 19. For fragments in F/I str. "e": Idem, TD IX, 190, Mc 71-4. B. BADER, TD XIII, 158-60, figs. 44.a-c.

75 Do. Arnold, Senwosret I, 114, fig. 59.2 shows at least one slightly smaller $(\mathrm{ca} .40 \mathrm{~cm})$ vessel of that type. The same feature can be observed in the tomb of Queen Weret (dating to Sesostris III.), where several storage jars of different sizes were found. S. AlLEN, Queens's Ware: Royal Funerary Pottery in the Middle Kingdom, in: C. J. Eyre (ed.), Proceedings of the Seventh International Congress of Egyptologists, OLA 82, Leuven 1998, 44-6, figs. 10.9, 10 (in the following S. Allen, Queens's Ware); Cf. B. BADER, TD XIII, 194. 
ly tied to later in the reign of Sesostris I. $^{76}$ Because rims, that can be attributed to that early type still appear at Tell el-Dabca in str. $\mathrm{H}(=\mathrm{d} / 2)$ it seems as if type 57 a continued through most of the $12^{\text {th }}$ Dynasty. ${ }^{77}$ The hiatus in area F/I between str. "e" and $\mathrm{H}(=\mathrm{d} / 2)$ prevents a continuous reconstruction of the development of type 57 a for Tell el-Dabca. As the period of mid to late $12^{\text {th }}$ Dynasty seems to be covered by the stratification of cEzbet Rushdi, it is hoped that more data will soon be available. A preliminary report seems to indicate that little variation in the form of this vessel type is to be expected. ${ }^{78}$ Inscriptions on pots show that this type was used for a variety of contents, which need not necessarily be identical throughout the lifetime of a vessel. ${ }^{79}$

Small globular jars, presumably like type 62 (Fig. 4), were found in the pyramid complex of Sesostris $\mathrm{I}^{80}$ and seem to live on till the end of the $12^{\text {th }}$ Dynasty.

From the early $12^{\text {th }}$ Dynasty onwards Marl C is used for "non-containers", such as potstands (type 68, Fig. 4). They are shaped like rings and sometimes show a pre-firing hole in their wall. In most cases they have outwards folded rims and bases. The rim diameters vary from about 20 to $26 \mathrm{~cm}$. This type is never very common, but persists from the beginning of the $12^{\text {th }}$ Dynasty to at least the late Second Intermediate Period. In Phase A Marl C was also used for construction elements such as drain pipes. ${ }^{81}$

\section{Phase B) Mid-12 ${ }^{\text {Th }}$ Dynasty}

The mid-12 $2^{\text {th }}$ Dynasty is not well known in terms of its ceramic sequence, but it seems that a few new shapes made from Marl C make their appearance, like types 11, dishes with inverted rims, ${ }^{82} 36$ and 40, medium jars, ${ }^{83}$

76 Do. Arnold, Senwosret I, 109-15, 143. For distribution see B. BADER, TD XIII, 158 .

77 Cf. S. Allen, Queens's Ware, 44-6, fig. 3.9, mother of Senwosret III.

78 E. CzERnY, Ä $\mathcal{F}^{2} L$ 8, 45.

79 Oil, myrrh - S. Allen, Queen's Ware, 46. Natron Engelbach, Gunn, Harageh, 3, 10, 32. Do. Arnold, Senwosret I, 109-10.

80 Do. ARnold, Senwosret I, 119, 120, 134, 143, fig., 74, nrs. 84.183, 84.184. B. BADER, TD XIII,199-200, figs. 60.f-h. A similar vessel type occurs at Elephantine in $11^{\text {th }}$ and $12^{\text {th }}$ Dynasty levels cf. C. v. PILGRIM, Elephantine XVIII, fig. 161.j.

81 Do. Arnold, Senwosret I, 29-30, chart 7, 121 and fig. 74.

82 B. BADER, TD XIII, 54, fig. 5.g.

83 B. BADER, TD XIII, 110, fig. 22.m, 122, fig. 28.e.

84 B. Bader, TD XIII, 145, fig. 39.a. C. v. PILGrim, Elephan-
47, large, bag-shaped jars with corrugated necks ${ }^{84}$ (see Fig. 3) and 60, jugs. ${ }^{85}$ In addition, type 62 , small globular jars continue (see above). The full publication of the material from ${ }^{c}$ Ezbet Rushdi will help to fill in the gaps in the mid $12^{\text {th }}$ Dynasty Marl C corpus.

\section{Phase C) Late $12^{\text {TH }}$ to early $13^{\mathrm{TH}}$ Dynasty}

Phase $\mathrm{C}$ is largely equivalent to str. $\mathrm{H}(=\mathrm{d} / 2)$ and G/4 (=d/1) at Tell el-Dabca, complex 6 at Dahshur and perhaps to building level 13 at Elephantine.

\section{Open Shapes}

The frequency of open vessels as compared to closed ones is considerably less in this phase as it was in Phase A, but in contrast to the latter a wider range of shapes is noticeable. Type 6 , deep bowls with a diameter between 16 and ca. $20 \mathrm{~cm}$ is present at Tell el-Dabca from strata G/4 to approximately E/ $2{ }^{86}$

Type 10, dishes with inner lips (Fig. 5), is only represented by rim fragments and can be dated to strata $\mathrm{G} / 4$ to $\mathrm{E} / 2-1$. The rim diameter varies from 16 to $21 \mathrm{~cm}$. Objects of the same type were found at Lisht $^{87}$ and Kahun ${ }^{88}$ and both date to the late Middle Kingdom. Carinated cups, type 12 (Fig. 5), are still found in this period, but only at Dahshur ${ }^{89}$ and Kom Rabica. $^{90}$

Footed bowls or "offering burners", type 17 (Fig. 5), appear fairly frequently amongst the repertoire at a number of sites in Egypt, but notably not in tombs. At Tell el-Dabca this type is represented from the late $12^{\text {th }}$ Dynasty (stratum $\mathrm{H}$ ) onwards till the end of the Second Intermediate Period (stratum D/2). The same time range is suggested by securely dated examples of this type found at Dahshur (complex 7$)^{91}$ and Kom Rabica. ${ }^{92}$ A very similar type made of Nile C clay

tine XVIII, fig. 160.j, fig. 161.c.

85 B. BADER, TD XIII, fig. 64.g.

86 B. BADER, TD XIII, 50-1, figs. 4, g-k. Kat.nr. 17, 6006 has been ascribed to the reuse of a grave (str. $d / 2)$ in str. c, R. Schiestl, pers. comm.

87 S. Allen, personal comm.

88 Cf. C. GALlorini, Incised Marks on Pottery and Objects from Kahun. Systems of Communication in Ancient Egypt During the Late Middle Kingdom, Ph.D., London, 1998. Chapter 2, Classes of Late Middle Kingdom Pottery, figs. 19.1-2, as lids.

89 Do. ArNold, MDAIK 38, 40, fig. 8.4, fig.11.2. BADER, TD XIII, 55-6.

90 See footnote 46.

91 Do. ArnOLD, MDAIK 38, Fig. 10. 15.

92 B. BADER, TD XIII, Kat.nr. 53, footnote 363. 
exists from the early $12^{\text {th }}$ Dynasty onwards ${ }^{93}$ continuing at least through the $13^{\text {th }}$ Dynasty. ${ }^{94}$

Two types of bowls, type 18, bowls with flat rims ${ }^{95}$ and especially type 23, the deep carinated bowls with rolled rims and raised or ring bases (Fig. 5), are more common and have been discovered at various sites in Egypt. Examples of these vessels vary consider- ably in size (diameter 26 to $50 \mathrm{~cm}$ ). At Tell el-Dabca carinated bowls show up from the late $12^{\text {th }}$ Dynasty to the end of the Hyksos Period (D/2), although it is possible that the few late examples have to be considered as residual sherds. ${ }^{96}$ The absence of type 23 from the earlier ceramic material of Tell elDabca, notably "stratum e" ${ }^{97}$ and the pyramid com-
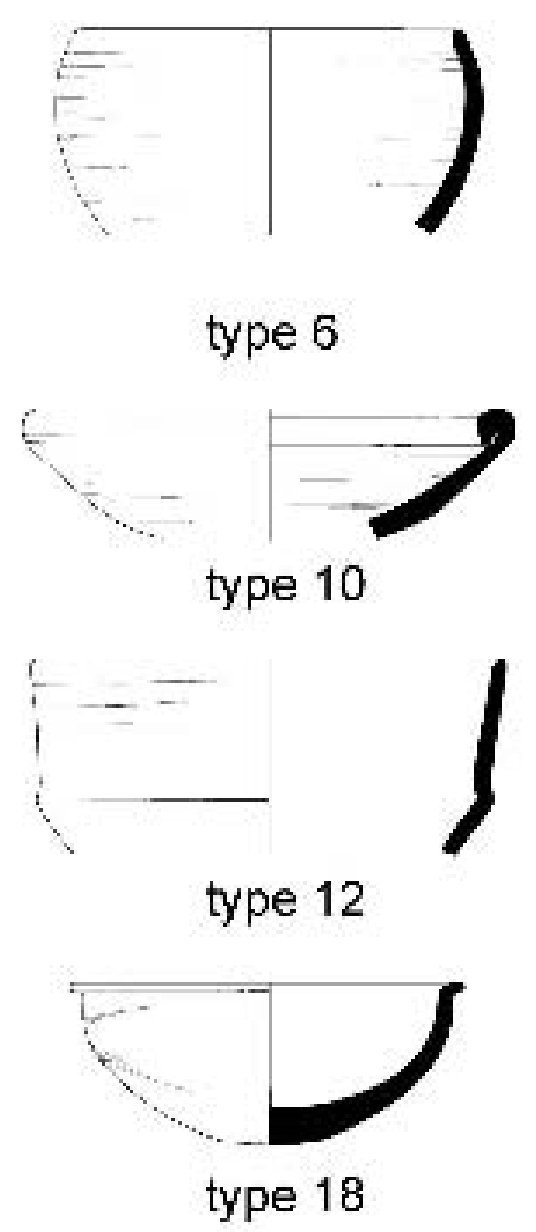
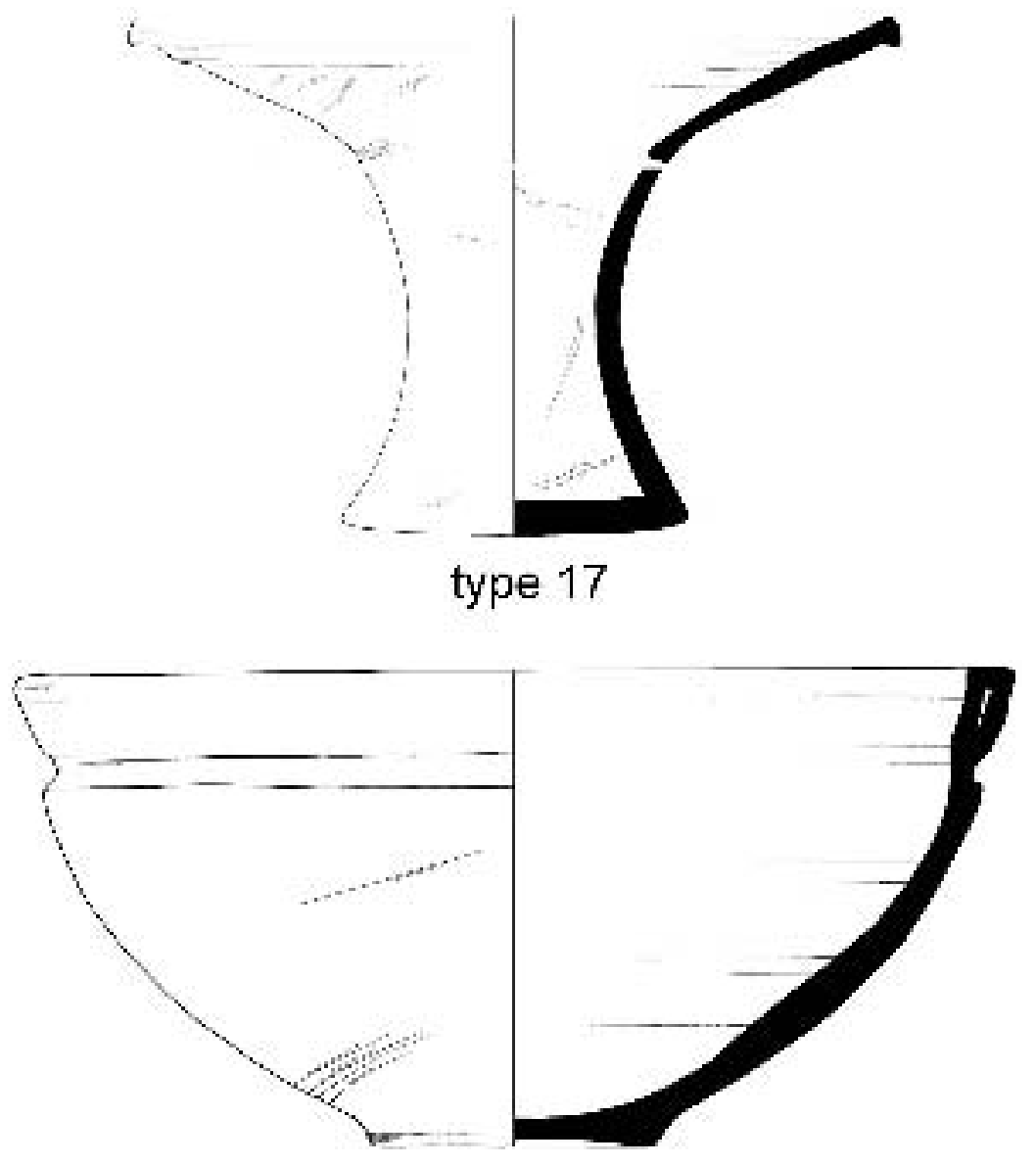

type 23

Fig. 5 Phase C, open shapes, scale $1: 4$

93 Do. Arnold, Senwosret I, 143, fig. 61. For one example of the late $12^{\text {th }}$ Dynasty see C. V. PILGRIM, Elephantine XVIII, Untersuchungen in der Stadt des Mittleren Reiches und der Zweiten Zwischenzeit, AV 91, Mainz 1996, fig. 150.h.

94 R. EngelbaCH, Riqqeh and Memphis VI, BSAE 25, London 1915, pl. XXXIII. R. Engelbach, B. Gunn, Harageh, BSAE 28, London 1923, Taf. XL $90 \mathrm{~d}, \mathrm{~g}, \mathrm{j}$ and $\mathrm{m}$.

95 B. BADER, TD XIII, 67-8, figs. 9.c-f.

96 B. BADER, TD XIII, 72-7. The finds at Tell el-Maskhuta, which have been synchronised with Tell el-Dabca strata $\mathrm{E} / 1-\mathrm{D} / 3$ could have given a hint in this question because type 23 was found there as well. Unfortunately it has only been stated that these bowls were made of Nileas well as Marl clay, and so we cannot be sure about a longer life span for this type. See C. A. Redmount, On an Egyptian/Asiatic Frontier: An Archaeological History of the Wadi Tumilat, Vol. I-IV, University of Chicago, Ph.D. Thesis, Chicago 1989, 805; and J. S. HolladaY, The Eastern Nile Delta During the Hyksos and Prae-Hyksos Periods; Towards A Systematic/ Socioeconomic Understanding, in: E. Oren (ed.), The Hyksos - New Historical and Archaeological Perspectives, Philadelphia 1997, 183-252. Statistical analyses (random sampling) on settlement ceramics show that type 23 is comparatively rare at Tell el-Dabca.

${ }^{97}$ E. CZERny, TD IX, passim. 
plex of Sesostris I at Lisht South ${ }^{98}$ shows that it does not occur that early, and only Dahshur complex $7^{99}$ and Lisht North ${ }^{100}$ provide examples that are both dated to the last two thirds of the $13^{\text {th }}$ Dynasty. Comparanda made of Marl $\mathrm{C}$ are also found at Kom Rabica/Memphis ${ }^{101}$ and Kahun. ${ }^{102}$

The similar type 24, deep carinated bowls with spouts (Fig. 6) is included here with type 23, because it is only by chance that a fragment with or without a spout is unearthed. Unfortunately too few examples of this type have been found in order to state firmly if there are any differences in the rim shape. The diameter seems to be always large $(>35 \mathrm{~cm})$. At Dahshur such a vessel already occurs in complex $6,{ }^{103}$ and they are also found at the sites of Harageh, ${ }^{104}$ Riqqeh ${ }^{105}$ and Askut. ${ }^{106}$ Therefore it seems reasonable to assume a date ranging from the late $12^{\text {th }}$ through the $13^{\text {th }}$ Dynasty. Another type of deep bowl with spout from Elephantine dated to the late $12^{\text {th }}$ Dynasty ${ }^{107}$ shows a different form, so that a considerable range of variation must be expected. Unfortunately only one welldated example exists from Tell el-Dabca coming from the transition from stratum $\mathrm{F}$ to $\mathrm{E} / 3$ (see Fig. 16). ${ }^{108}$

The so-called "fish-dishes", ${ }^{109}$ type 25 , are only dealt with briefly here, as they have been treated quite thoroughly elsewhere and will get further attention by the author in the excavation memoir of the site RAT at Kom Rabica/Memphis. ${ }^{110}$ This class of vessels is somewhat special, because it is the only extensively decorated pottery type of the late Middle Kingdom. Moreover it differs markedly in technique being handmade and decorated before firing with elaborate incised motifs. The distinctive oval shape links this type with pottery of the $1^{\text {st }}$ Dynasty and suggests a purely Egyptian origin, ${ }^{111}$ although intermediary stages so far could not be found. Suffice it to say that we are confronted with settlement pottery that can be divided into several groups: type $25 \mathrm{a}$ (Fig. 6), which occurs from stratum $\mathrm{G} / 4(=\mathrm{d} / 1)$ onwards at Tell el-Dabca, with representations of a pond in the middle of the dish encircled by waterplants and type $25 \mathrm{~b}$, of a large fish, presumably the species tilapia, ${ }^{112}$ surrounded by flora or other animals like fish, horned animals and birds. This latter

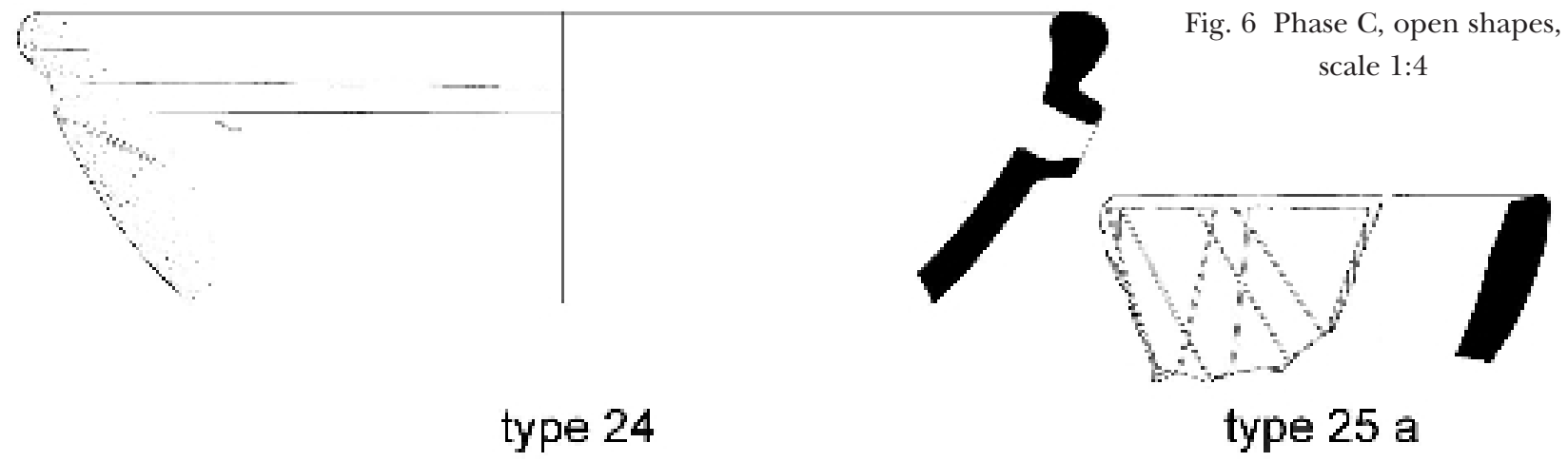

${ }^{98}$ Do. Arnold, Senwosret I, passim.

${ }^{99}$ Do. Arnold, MDAIK 38, 47, fig., 11.1.

${ }^{100}$ Do. ARnold, F. ARnold, S. Allen, Canaanite Imports at Lisht, the Middle Kingdom Capital of Egypt, $\ddot{A} \mathcal{E} L 5$ (1995), 22, 24, Fig., 5.3.

${ }^{101}$ Approximately from the mid $13^{\text {th }}$ Dynasty to the late SIP (level VIIb to VIb), J. Bourriau, pers. comm.

${ }^{102}$ J. Bourriau, S. Quirke, The Late Middle Kingdom Ceramic Repertoire in Words and Objects, Lahun Studies, Reigate, Surrey 1998, figs. 5.1-2.

${ }^{103}$ Do. ARNOLD, MDAIK 38, Fig., 8.1.

${ }^{104}$ S. Tyson Smith, Askut in Nubia, London, New York 1995, fig. 3.7/H.

${ }^{105}$ R. EngELbaCh, B. Gunn, Harageh, pl. XL, type $70 \mathrm{q}$ and $\mathrm{r}$.

${ }^{106}$ R. ENGELbaCH, Riqqeh, pl. XXXLLL, type $70 \mathrm{q}$ and r.

107 C. v. PILGRIM, Elephantine XVIII, 340, fig. 151.a.

108 B. BADER, TD XIII, 79, Kat.nr. 93.

${ }^{109}$ B. BADER, TD XIII, type 25, 79-99.

${ }^{110}$ By courtesy of the Egypt Exploration Society and J. Bourriau.

111 Cf. W. M. F. Petrie, Tarkhan and Memphis V, London 1913, pl. XLVI. 11b. W. van HaARLEM, A Tomb of the First Dynasty at Tell Ibrahim Awad, OMRO 76 (1996), 10, 48, Pl. 4, 6, Nile C. For further references see B. BADER, TD XIII, 81, footnote 433 .

112 Cf. M. Dambach, I. Wallert, Das Tilapia-Motiv in der altägyptischen Kunst, CdE 41 (1966), passim. D. SAHRHAGE, Fischfang und Fischkult im Alten Ägypten, Mainz 1998, fig. 25. 
type is only rarely found in dateable contexts like some examples that are assigned to stratum E/3-2 $(=\mathrm{b} / 2-1)$ and $\mathrm{E} / 1-\mathrm{D} / 3(=\mathrm{b} / 1-\mathrm{a} / 2)$. Another group (type 25 variant), which is interestingly not represented amongst the material neither from Tell el-Dabca nor Kom Rabica/RAT, shows mainly geometric patterns. This third type of oval dish was found in considerable numbers at the town site of Kahun ${ }^{113}$, although the other two types mentioned above also appeared there. ${ }^{114}$ It seems that the patterns develop over time, for example from a real fish to that having a head at each end such as the vessel from Qau/Antaeopolis. ${ }^{115}$ It is possible that the geometric patterns are derived from the pond-motive, especially because these dishes usually have a crosshatched area in the middle.

With the evidence available, we can only speculate on the possible use of "fish-dishes". Often this class is referred to as a device for removing husks from grain, since grain was found in an incision of one such dish ${ }^{116}$ and some dishes show extensive signs of wear in the middle. ${ }^{117}$ This holds true for several specimens of this type. Of 23 examples with sufficiently preserved bases, 15 showed signs of wear, but 8 did not. It seems important to note that the dishes with linear pattern seem to have been used particularly in this way, but not the examples with an actual fish motive. So one can easily accept the idea that some examples of this type were employed as grating devices. Other somewhat improbable theories for the use of "fish-dishes" include scaling fish (unhandy), ${ }^{118}$ watering of flowers (pattern not visible), ${ }^{119}$ serving food (too heavy, they weigh $6 \mathrm{~kg}$ empty) or cultic purposes as a kind of "house altar". These suggestions are not really satisfactory.

The date of the appearance of this type can be defined fairly closely, because it is missing from the repertoire of the early 12th Dynasty (pyramid complex of Sesostris I or Tell el-Dabca F/I-str. "e"), but by the late $12^{\text {th }} /$ early $13^{\text {th }}$ Dynasty (Tell el-Dabca str. $\mathrm{G} / 4$ ) a number of examples are found. This situation is paralleled at Dahshur ${ }^{120}$ and Lisht ${ }^{121}$ and presumably also at Memphis. ${ }^{122}$ Type 25 continues to exist at Tell el-Dabca until str. E/1-D/3, but these pieces should probably be considered as remnants, because at Tell el-Maskhuta not a single fish dish fragment has been unearthed in levels contemporary with Tell el-Dabca phases E/1-D/3. On the basis of parallels ${ }^{123}$ for type 25 from Tell el-Yahudiyeh, Tell Hebwa, Memphis, Kahun, Dahshur, Lisht, Qau/Antaeopolis, Abydos (?), Buhen and Askut in Nubia it seems clear, according to the accessible data, that we are concerned with a "Northern" Egyptian type that has been transported to, or imitated ${ }^{124}$ in, Nubia. Further work will show if this hypothesis is true or not, but so far no such pieces are known from south of Abydos to Elephantine.

\section{Closed shapes}

By the late $12^{\text {th }}$ to early $13^{\text {th }}$ Dynasty the variety of jar rims seems to be confined to types $34 \mathrm{a}$ - jars with longer necks and folded rims, ${ }^{125} 36 \mathrm{a}$ and $\mathrm{b}$, medium-sized jars (Fig. 7), 41, ${ }^{126}$ jars with everted rims, 46, large jars with corrugated necks (Fig. 7) and 47, large bag-shaped jars (Fig. 7).

The class of medium-sized jars can be divided according to their manufacturing technique i.e. handmade vessels with the rim turned on a turntable - type 36 a, and completely wheelmade vessels - type $36 \mathrm{~b}$ (Fig. 7). This class occurs quite frequently at Tell el-Dabca from str. $\mathrm{H}(=\mathrm{d} / 2)$ to about $\mathrm{D} / 3(=\mathrm{a} / 2)$ in settlement layers as well as in tomb contexts. It seems to have been a sort of "all purpose vessel" for storage and even for cooking
113 W. M. F. Petrie, Illahun, Kahun and Gurob, London 1891, pl. V.6, 7. Idem, Kahun, Gurob and Hawara, London 1980 , pl. XIII.106, 108, 111. Some of the material is now at the University College London, Petrie Museum, where I had the chance to look at it more closely. My warmest thanks for this possibility go to Barbara Adams ( $\dagger)$, then curator of the collection.

114 W. M. F. PETRIE, Illahun, Kahun and Gurob, pls. V.1, 2, 3, 4.

115 W. M. F. PetrIE, Antaeopolis, London 1930, pl. XXI.4.

${ }^{116}$ J. Bourriau, Memphis. Kom Rabica, BCE XIII, (1988), 31.

117 S. T. SмIтH, Askut in Nubia, London, New York 1995, 196, footnote 62 . Not published.

118 Cf. S. Ikram, Choice Cuts: Meat Production in Ancient Egypt, Leuven 1995, 73-4.
${ }^{119}$ W. KrönIG, Ägyptische Fayence-Schalen des Neuen Reiches, MDAIK 5 (1934), 157.

${ }^{120}$ Do. ARNOLD, Zur Keramik aus dem Taltempelbereich der Pyramide Amenemhets III. in Dahschur, MDAIK 33, fig. 1, 21-2, 26. Do. ARNOLD, MDAIK 38, fig. 11.11.

121 Do. Arnold, F. Arnold. S. Allen, Canaanite Imports at Lisht, the Middle Kingdom Capital of Egypt, ÄEL 5, 22-24, figs. 5.1, 2. Nr. PA 10 und PA 1306.

${ }^{122} \mathrm{~J}$. Bourriau, pers. comm.

${ }^{123}$ For references see B. BADER, TD XIII, 81-3.

${ }^{124} \mathrm{~J}$. Bourriau, Egypt and Africa, 130, footnote 33.

125 B. BADER, TD XIII, 107, fig. 22.g. For one possible complete shape cf. C. v. PILgrIm, Elephantine XVIII, 156.a.

${ }^{126}$ B. BADER, TD XIII, 124 
40

Betting Bader

Fig. 7 Phase C, closed shapes, scale 1:4

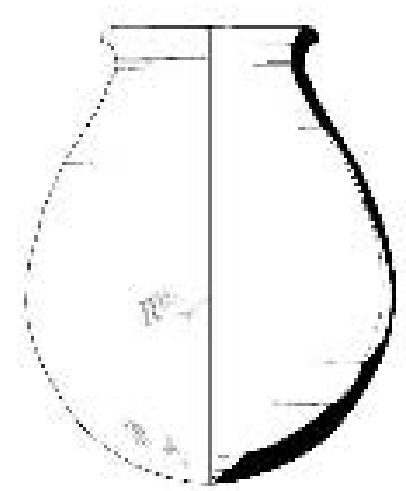

type $36 \mathrm{~b}$

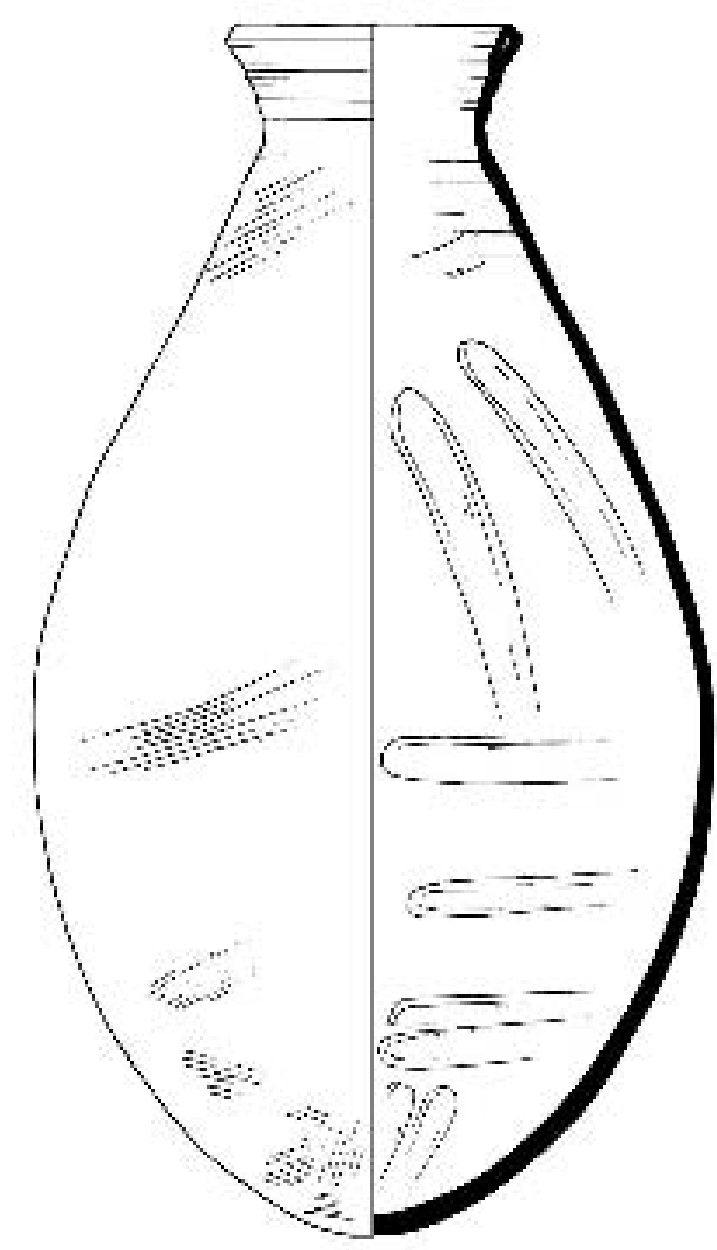

type 46

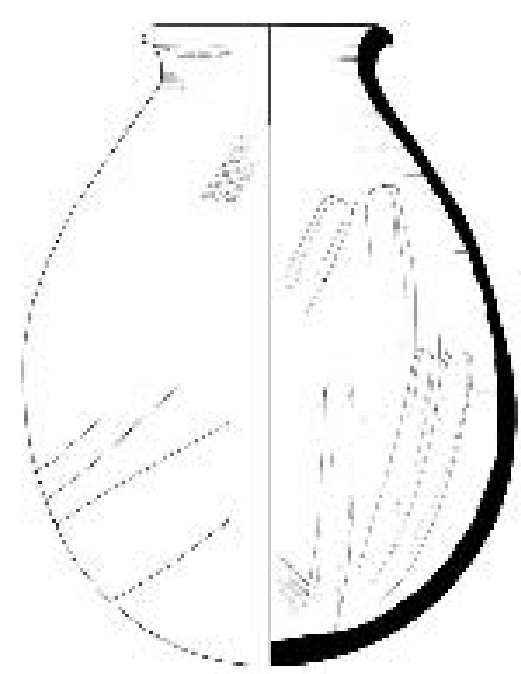

type 35 a

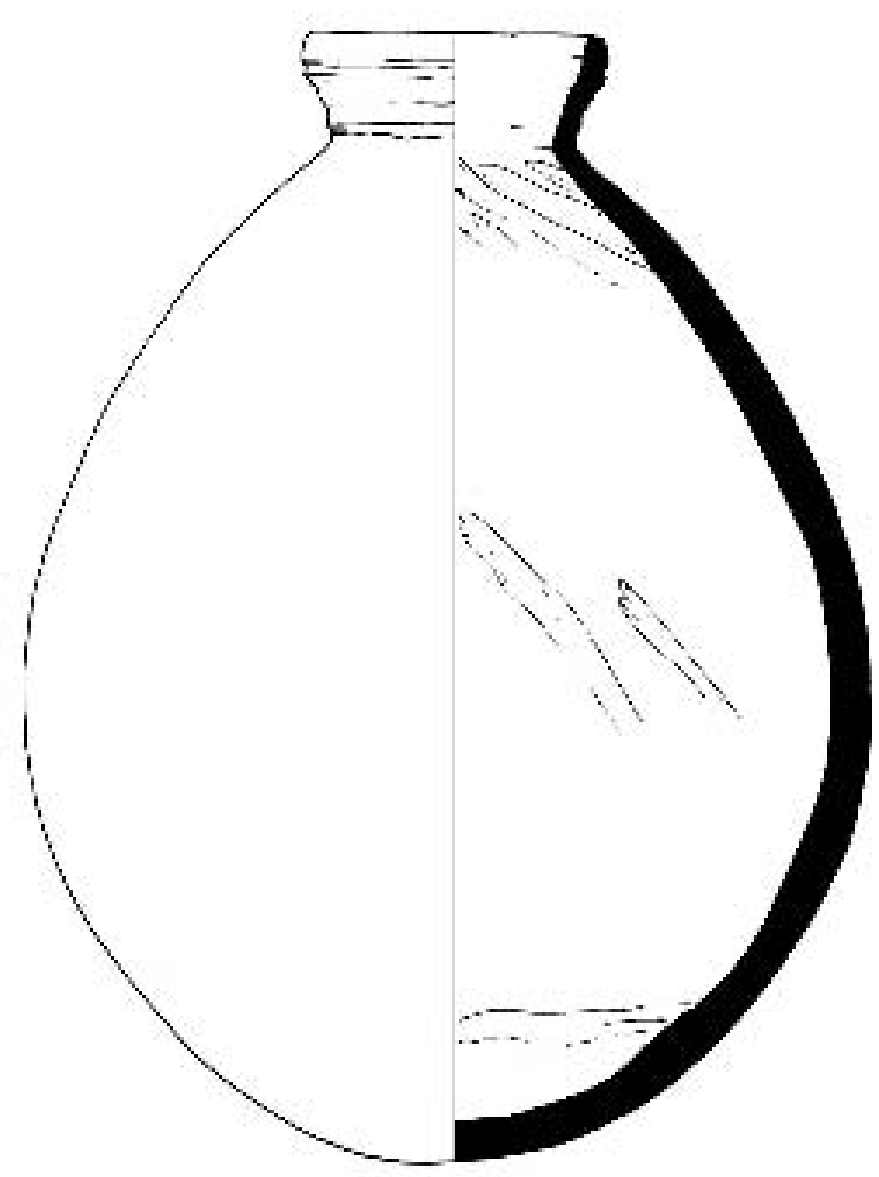

type 47 
(some specimens were heavily burnt on the outside). It appears that vessels of this shape begin to occur in the mid-12th Dynasty as they are missing from area F/I str. "e" as well as from the pyramid complex of Sesostris I at Lisht South. Their appearance in complex 6 at Dahshur ${ }^{127}$ dated from the late $12^{\text {th }}$ to early $13^{\text {th }}$ Dynasty, gives additional evidence for the date range of that type. Rims of such vessels can be recognised by their uniformly everted shape with slightly bulging lip and almost no neck. The range of rim diameter (6 to $12 \mathrm{~cm}$ ) suggests a variety of sizes. Do. Arnold found that at Dahshur the shape of the body changed over time. The earliest stage is the globular shape. ${ }^{128}$ At about the same time a rather bag-shaped variety also exists. Both of these were then replaced by a shape with an elongated body in the late $13^{\text {th }}$ Dynasty. ${ }^{129}$ This development could not be detected at Tell el-Dabca, where the elongated variety is rare all together. ${ }^{130}$ Parallels were found at Lisht North, ${ }^{131}$ Kahun, ${ }^{132}$ Qasr elSagha, ${ }^{133}$ Quila el-Dabba, ${ }^{134}$ Serabit el-Khadim ${ }^{135}$ and Elephantine. ${ }^{136}$

Type 46, large jars with corrugated necks (Fig. 7) can be considered as a typical find on any site of Middle Kingdom or Second Intermediate Period date. ${ }^{137}$ Its egg-shaped body with slightly funnel-like, folded and corrugated rim is very characteristic. The height of such jars varies from 40 to $50 \mathrm{~cm}$. The manufacturing technique is the same as for type 36 a and the large storage jars, type 57: the body was visibly handmade whereas the rim was turned on the wheel or a turntable. This type of vessel does not occur in the early $12^{\text {th }}$ Dynasty, as no examples have been found

${ }^{127}$ Do. ARNOLD, MDAIK 38, fig. 8.6.

${ }^{128}$ Do. ARNOLD, MDAIK 38, fig. 19.1. The same feature can be observed at Elephantine, but in the early Middle Kingdom levels 14-5. C. v. PILGRIM, Elephantine XVIII, figs. 160.h, i.

129 Do. ARNold, MDAIK 38, 62-4, fig. 12.1.

${ }^{130}$ At Kom Rabica only rim fragments were found. See B. BADER, TD XIII, 108-21. Cf. for further parallels of shape.

131 S. Allen, pers. comm.

${ }^{132}$ J. Bourriau, Umm el-Gacab, 66, nr. 119.

133 Do. ARnold, Qasr el-Sagha, 34, fig. 19.7.

134 Do. ARnold, Quila el-Dabba, 45, 55, pl. 11.n, 62 G.

${ }^{135}$ J. Bourriau, CRIPEL 18 (1996), fig. 4.10.

136 C. v. PILGRIM, Elephantine XVIII, 338, fig. 150.f, 348, fig. 155.d, 358, figs. $160 . \mathrm{h}$, i: $11^{\text {th }}$ to $12^{\text {th }}$ Dynasty with slightly different form of rim.

${ }^{137}$ At Kom Rabica, Memphis this type exists through all levels of the SIP. J. Bourriau, pers. comm. at Lisht South or Tell el-Dabca area F/I str. "e". At Dahshur, complex $6,{ }^{138}$ and at Tell el-Dabca str. H $(=\mathrm{d} / 2),{ }^{139}$ both dated to the late $12^{\text {th }}$ Dynasty, such vessels were already common. Thus, we may expect a mid-12 ${ }^{\text {th }}$ Dynasty date for its first appearance. Do. Arnold came to the same result in the Lisht region. ${ }^{140}$ The virtual disappearance of jars with corrugated necks seems to occur with stratum E/1 latest at Tell el-Dabca. ${ }^{141}$ By contrast this type continues to the late SIP at Kom Rabica. This could suggest that contacts between the Eastern Delta and the Memphis-Fayoum region in this period were extremely restricted if not cut off altogether (see below).

A special feature of the rims of type 46 - a rounded lip that is turned slightly inwards - seems to be confined to the earlier levels (H-G/3-1) at Tell el-

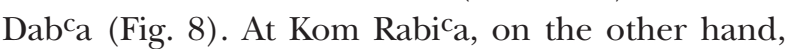
this feature is present in all the levels of the later Middle Kingdom and SIP, respectively. ${ }^{142}$

Inscriptions found on some vessels indicate that they were used for water, wine and perhaps even for beer. ${ }^{143}$ Parallels are known from North Sinai, ${ }^{144}$ Ser-

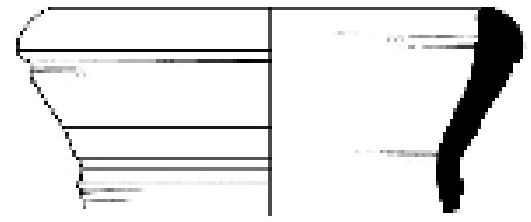

Fig. 8 Phase C, scale 1:2

${ }^{138}$ Do. ARNOLD, MDAIK 38, figs. 8.8-12.

${ }^{139}$ B. BADER, TD XIII, 129-31.

${ }^{140}$ Do. Arnold, Pyramidcomplex, 77.

141 The only two vessels, previously dated to str. D/3, have been reconsidered and ascribed to late in str. E/1 because of the accompanied finds, pers. comm. I. Forstner-Müller. Cf. M. BIETAK, Egypt and Canaan During the Middle Bronze Age, BASOR 281 (1991), 43. B. BADER, TD XIII, 142-3. In konvolutes of area A/II they occur in stratum E/1 at the latest. I. Forstner-Müller, pers. comm.

${ }^{142} \mathrm{~J}$. Bourriau, pers. comm.

143 Do. Arnold, Wüstentone, 185-6. Do. Arnold, Pyramidcomplex, 77, nr. 233, pl. 95.

${ }^{144}$ E. D. Oren, The "Kingdom of Sharuhen" and the Hyksos Kingdom, in: E. D. Oren (ed.), The Hyksos - New Historical and Archaeological Perspectives, Philadelphia 1997, 267, figs. 8.23/16. 
abit el-Khadim, ${ }^{145}$ Dahshur, ${ }^{146}$ Lisht,,${ }^{147}$ Harageh, ${ }^{148}$ Hawara, ${ }^{149}$ Kahun, ${ }^{150}$ Qasr el-Sagha,${ }^{151}$ Herakleopolis Magna, ${ }^{152}$ Elephantine, ${ }^{153}$ and the fortress at Askut. ${ }^{154}$ The same shape occurs at Beni Hasan ${ }^{155}$ and is known from cemeteries of the Kerma culture in Nubia: Ukma, Sai, Kerma and perhaps Mirgissa. ${ }^{156}$ At Abydos the same shape occurs, but made of the Upper Egyptian Marl A4. ${ }^{157}$ If we assume that Marl C storage vessels and their associated contents were distributed from the capital at 'It-3wj in the northern part of Egypt in a centralised way, we can see that the southern part of the country, Elephantine and the fort at Askut, received goods from this commodity distribution system. But as the same vessel type occurs in a local clay, this must mean that the kind of commodities distributed in them is not tied to a specific shape of vessel. This leads further to the question with which part of the country the people of the Kerma culture maintained trade relations. The clay of the vessels in question is sometimes described as "type Qena". ${ }^{158}$ But there are also vessels from Kerma itself that were securely identified as Marl C. ${ }^{159}$ It seems evident that the trading patterns between

Fig. 9 Phase C, closed shapes, scale 1:8
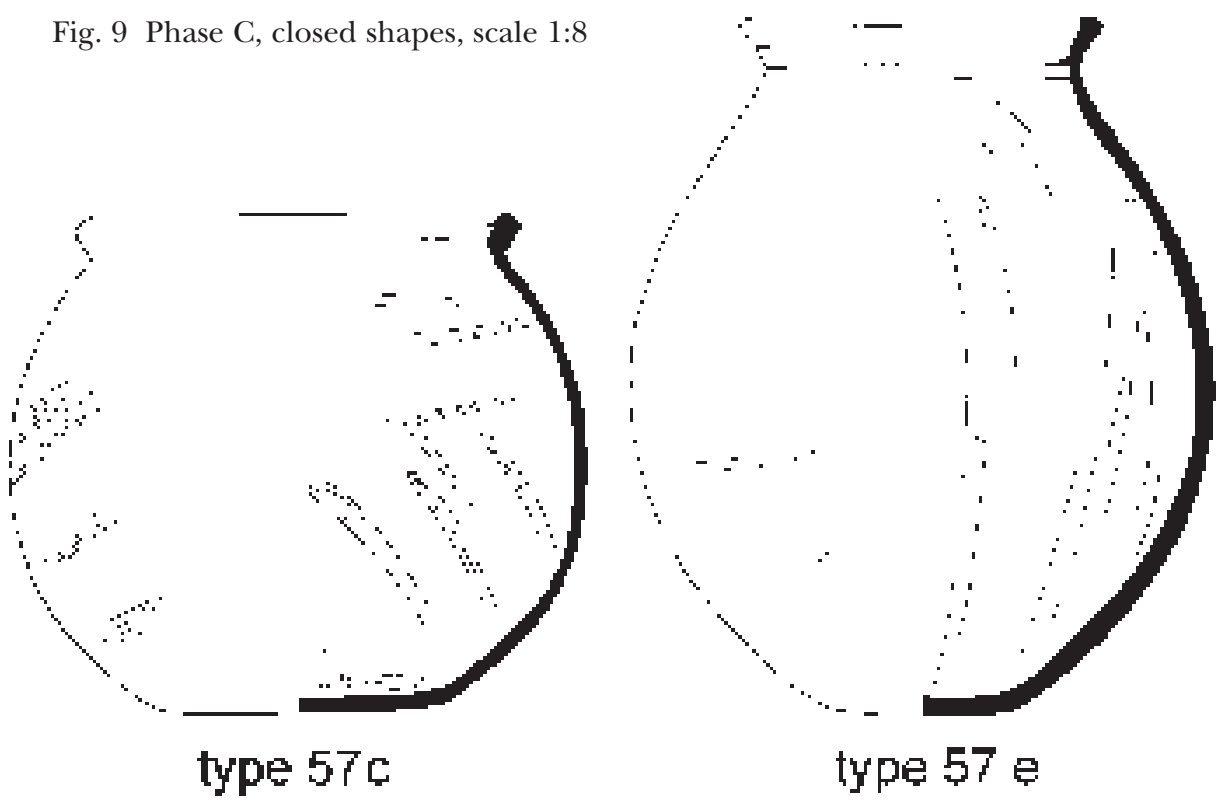

${ }^{145}$ J. Bourriau, CRIPEL 18, fig. 2.10, fig. 4.11.

146 J. DE Morgan, Fouilles à Dahchour, Mars-Juin 1894, Vienna 1895, 73-4, fig. 164.

147 Do. Arnold, Senwosret I, 122, fig. 74. Do. Arnold, F. Arnold, S. Allen, Canaanite Imports at Lisht, the Middle Kingdom Capital of Egypt, $\ddot{A} \mathcal{E} L 5$ (1995), 22, 24, 26, fig. 5.8.

148 R. Engelbach, B. Gunn, Harageh, BSAE 25, London 1923, pl. 38, type 46 m. Cf. Do. Arnold, Wüstentone, colour pl. IIIb,

${ }^{149}$ W. M. F. Petrie, G. A. Wainwright, The Labyrinth, Gerzeh and Mazghuneh, BSAE 21, London 1912, pl 35.105. U.C. 18489. The author had the chance to see this object by the kind permission of the then in charge curator Barbara Adams (†). It is Marl C.

${ }^{150}$ J. Bourriau, S. Quirke, The Late Middle Kingdom Ceramic Repertoire in Words and Objects, Lahun Studies, Reigate, Surrey 1998, 68, figs. 1.10-2.

${ }^{151}$ J. SLIwA, Studies on the Middle Kingdom and the Second Intermediate Period Settlements in 1979-1988, Qasr

el-Sagha, Fontes Archaeologici Posnanienses 36 (1987/88), 208-9, 212, fig. 23, fig. 25.

${ }^{152}$ Identified by the present writer, with kind permission of M. del Carmen Pérez-Die.

${ }^{153}$ T. Rzeuska, Stadt und Tempel von Elephantine, MDAIK 55 (1999), fig. 45.5.

154 S. T. SмIтH, Askut in Nubia, London, New York 1995, fig. $3.6 \mathrm{~A}$

155 J. Garstang, The Burial Customs of Ancient Egypt, London 1907, pl. XV, 43, 47. pl. X, fig. 200 upper right and lower right.

${ }^{156}$ See References in B. BADER, TD XIII, 130.

157 J. Wegner et. al., $\ddot{A} \mathcal{E} L$ 10, fig. 9.32, fig. 17.45. The latter also shows a smaller variant within the type. A smaller type made from Marl C seems to exist at Memphis, but is very rare, J. Bourriau, pers. comm.

158 A. VILA, Le cimetière kermaïque d'Ukma Ouest, Paris 1987, fig. 227.157/3.

${ }^{159}$ J. Bourriau, Egypt and Africa, 129, footnote 12, pl. 6.1. 
Egypt and Nubia are much more complex than hitherto thought.

The closely connected type, 47, large bag-shaped jars with corrugated necks (Fig. 7) is still found at Elephantine until the end of the $12^{\text {th }}$ Dynasty (see above). ${ }^{160}$

The storage jars of this period (equivalent to strata $\mathrm{H}(=\mathrm{d} / 2)$ and $\mathrm{G} / 4(=\mathrm{d} / 1)$ at Tell el-Dabca) are represented by types $57 \mathrm{~b}, \mathrm{c}$ and e. ${ }^{161}$ Complete examples of type $57 \mathrm{~b}$ were found in the cemeteries of Harageh and Riqqeh, where they were recorded under corpus type number 67 e. ${ }^{162}$ Type 57 c (Fig. 9) is only known through one complete example and there are indications that several different shapes of bodies existed at the same time. ${ }^{163}$

Zeir type 57 e (Fig. 9) begins to appear at this same time, but not very frequently. From str. G/3-1 onwards the frequency increases (see below).

Starting in this period a group of closed vessels with spouts develops. These are divided by size into two subgroups: type 54, large pots with spouts and 55, small pots with spouts (Fig. 10). They may already occur as early as str. G/4 (=d/1) at Tell el-Dabca and continue to be used almost to the end of the $13^{\text {th }}$ Dynasty (str. E/3 (=b/2)). Parallels that are definitely made from Marl C were found at Kahun, ${ }^{164}$ Lisht North ${ }^{165}$ and Kom Rabica. ${ }^{166}$ The shape of the rim fragments indicates a certain degree of variation. In working only with rims it is difficult to separate the types as the rims of type 54 are similar to those of zeirs, type 57 . Unfortunately the rims of spouted pots are not so uniform that we could consider every such rim (even if found without the actual spout) as belonging to type 54. On the other hand no examples of similar rims have been found sufficiently preserved to prove that the type without spout also existed. More material is needed to resolve this question.

Type $68,{ }^{167}$ large potstands (Fig. 10), continues to be used, whereas the only example of an offering stand, type 69 (Fig. 10), is attested in str. H (= $\mathrm{d} / 2) .{ }^{168}$ The use of Marl $\mathrm{C}$ ceramics for drain pipes is maintained. ${ }^{169}$

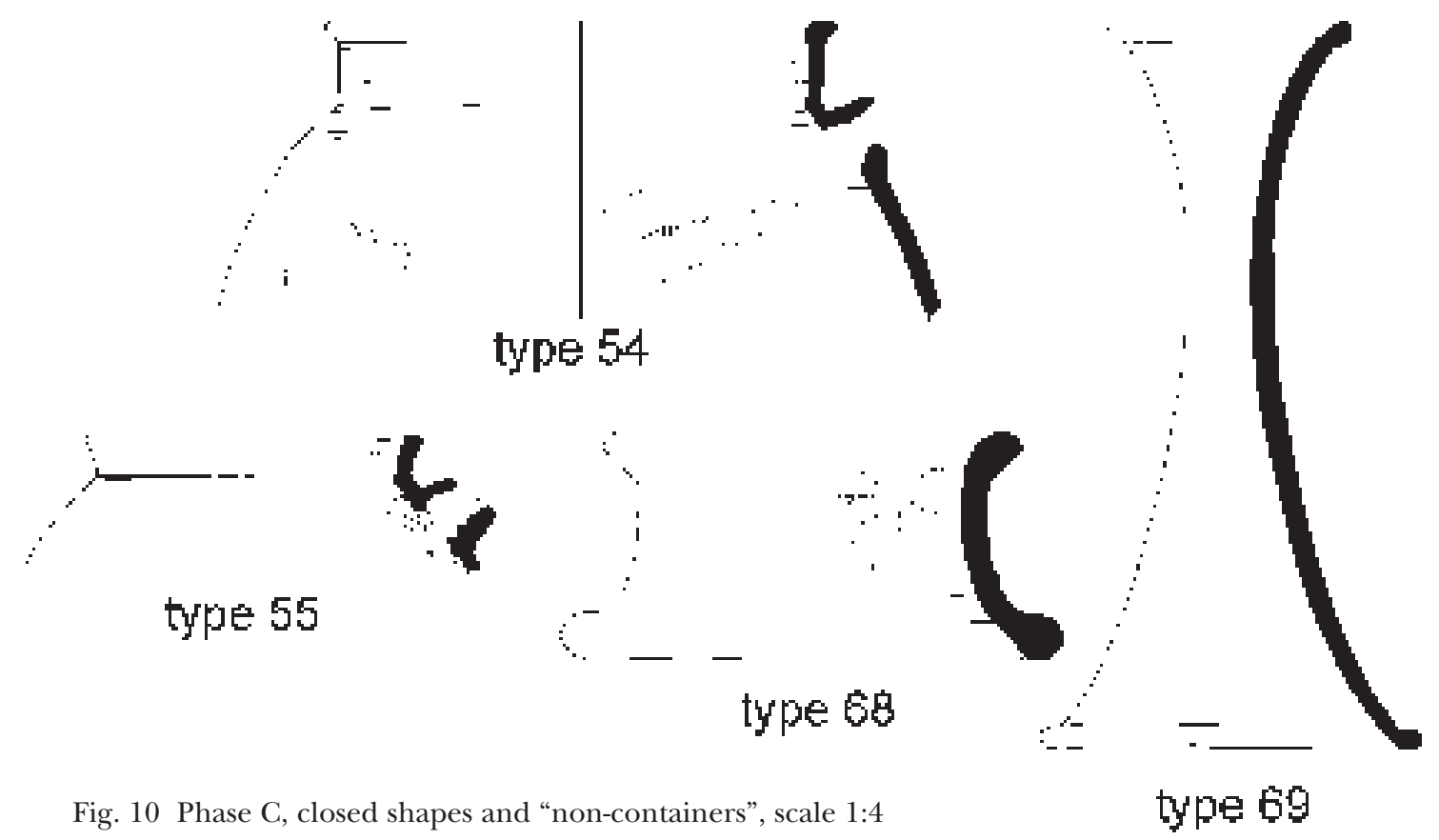

\footnotetext{
${ }^{160}$ See footnote 84 .

${ }^{161}$ B. BADER, TD XIII, 160-3, 166-78. For rim types of that period see fig. 42.

162 Engelbach, Gunn, Harageh, pl. 35. Engelbach, Riqqeh, pl. 32.

163 B. BADER, TD XIII, 160-3.
}

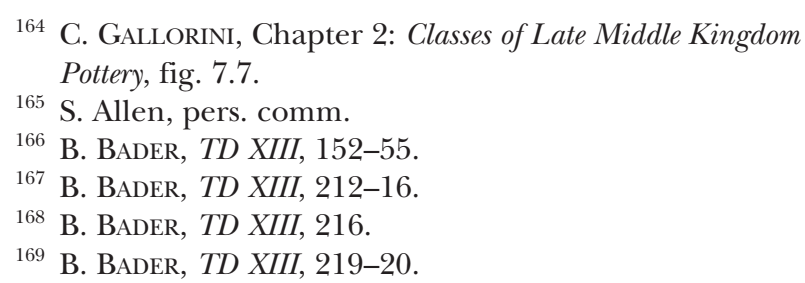




\section{Phase D) The mid $13^{\text {Th }}$ Dynasty}

Most of the Marl C vessels which characterise the corpus of Phase D were found in str. G/3-1 (=c) at Tell el-Dabca, complex 7 at Dahshur, the lower levels of Kom Rabica/Memphis and at Kahun. During this time and the remainder of the $13^{\text {th }}$ Dynasty the variety of Marl C vessel types (Fig. 11) reaches its high point, at least according to our current knowledge. ${ }^{170}$

A decrease of types is only attested for Tell el$\mathrm{Dab}^{\mathrm{c}} \mathrm{a}$ in a later stage (strata E/2-D/2). At other sites in the Memphis-Fayoum region the number of types seems to stay at a higher level. We can perhaps assume from this evidence, that the contacts between the Eastern Nile Delta and the Nile valley proper were rather restricted in this later time that corresponds in the Delta to the Hyksos period (see below).

\section{Open shapes}

While ordinary dishes, type $2^{171}$ (Fig. 12), are still in use at Kom Rabica, only a few examples of small bowls with direct rims, type 5 (Fig. 12), occur at Tell el-Dabca in strata $\mathrm{G} / 3-1$ to $\mathrm{E} / 3$. Comparanda are known from Wadi Tumilat, Kom Rabica/Memphis and Lisht, and reflect a similar time range for this type. ${ }^{172}$
Type 6, deep bowls (Figs. 5, 15), type 10, dishes with inner lips (Fig. 12), 12, carinated cups (Fig. 12), 17, footed bowls (Fig. 12), 18, bowls with flat rims (Fig. 12), and 23, large carinated bowls (Fig. 13), continue to be found (see above). Type 20, bowls with simple contour, rolled rims and ring bases (Fig. 13), are found at Kom $\mathrm{Rabi}^{\mathrm{C} a}$ /Memphis in levels that are currently equated with the second half of the $13^{\text {th }}$ Dynasty. Examples of type 20 at Tell el-Dabca date to a later period. ${ }^{173}$

Fish dishes with representations of ponds in the mid$d l e$, type 25 a (Fig. 13), survive, and a variant shape, represented by dishes with raised centres, type $25 \mathrm{c}^{174}$ (Fig. 13), is added to the repertoire. Parallels for the latter exist at Kahun. ${ }^{175}$

\section{Closed shapes}

A variety of rims of jars, types 32, 33, 34, 34a, 42 and 45 occur in levels dated to the last two thirds of the $13^{\text {th }}$ Dynasty. ${ }^{176}$ Rims of the same types occur in the Memphis/RAT repertoire in about the same time range. ${ }^{177}$ About the shape of the body nothing much can be said, as reconstructable jars are only rarely represented amongst the sherd material. ${ }^{178}$

The ubiquitous types $36 \mathrm{a}, \mathrm{b}$, medium-sized jars (Fig. 14) and 46, jars with corrugated necks (Fig. 14), continue in the ceramic collections (see above).
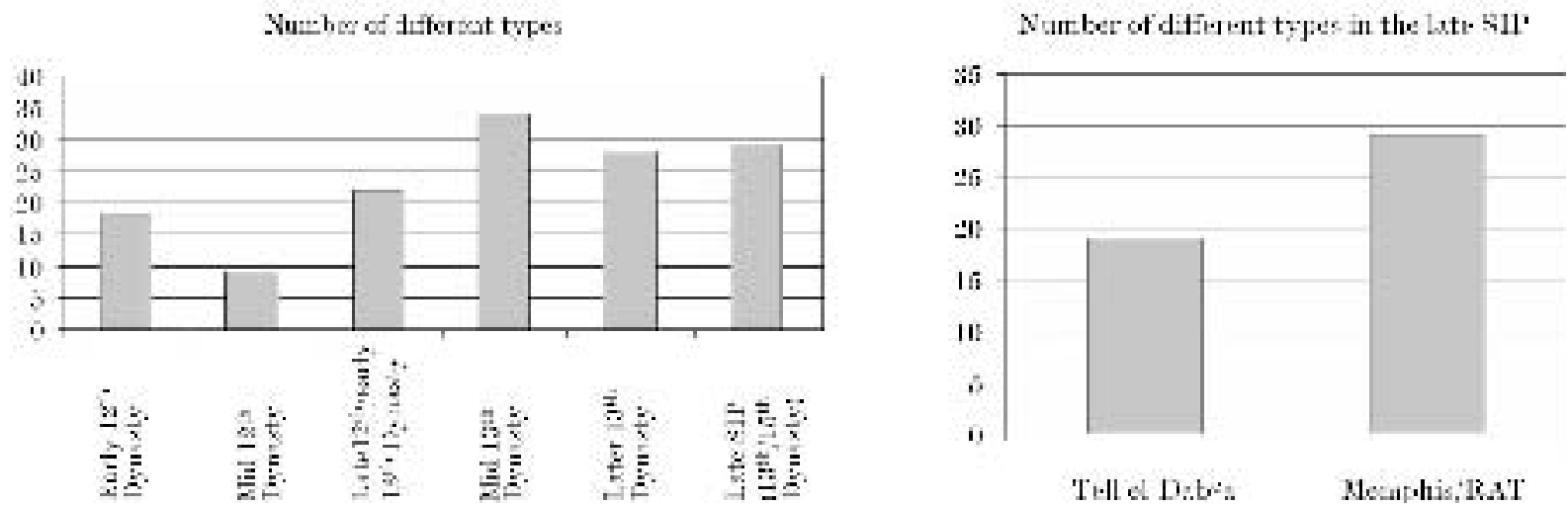

Fig. 11 Variety of Marl C vessel types

170 The reason for the low number of different types in mid $12^{\text {th }}$ Dynasty may lay in the current state of research.

${ }^{171}$ B. BADER, TD XIII, 45-7.

172 C. A. Redmount, Wadi Tumilat, fig. 86.26. $(\mathrm{Md} .=12.3)$. B. BADER, TD XIII, 48-50, Kat.nr. 15, 16. S. Allen, MMA, pers. comm.

173 B. BADER, TD XIII, 68-70.

174 B. BADER, TD XIII, 97, figs., 20.e, f.

175 W. M. F. Petrie, Kahun, Gurob and Hawara, pl. XIII. 107, U.C. 7591.
${ }^{176}$ Str. G/3-1 at Tell el-Dabca. B. BADER, TD XIII, 104-7, 124, 127-8, figs. 22.d, g, h, i, 28.f, 29.c. Complex 7 at Dahshur Do. ARNOLD, MDAIK 38, figs. 11.6, 11.8, 11.9. Same in B. BADER, TD XIII, figs., 22.a, c, i.

177 Pieces in early $18^{\text {th }}$ Dynasty contexts are considered to be residual. B. BADER, TD XIII, 104-7, figs. 22.b, e, f, j, k.

${ }^{178}$ Rare examples with complete profiles at Kom Rabica/ Memphis indicate a squat form, J. Bourriau, pers. comm. 


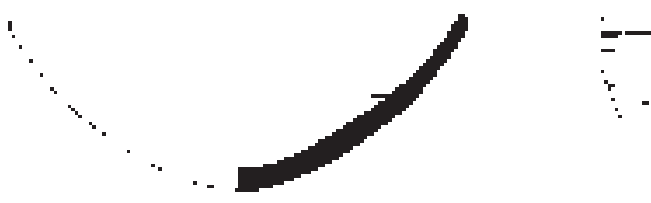

type 2 type 5

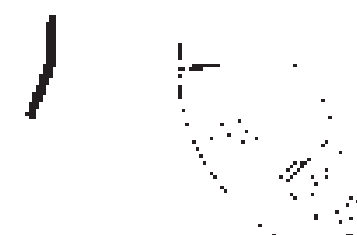

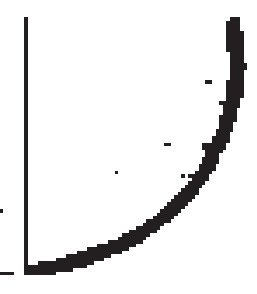

type 6
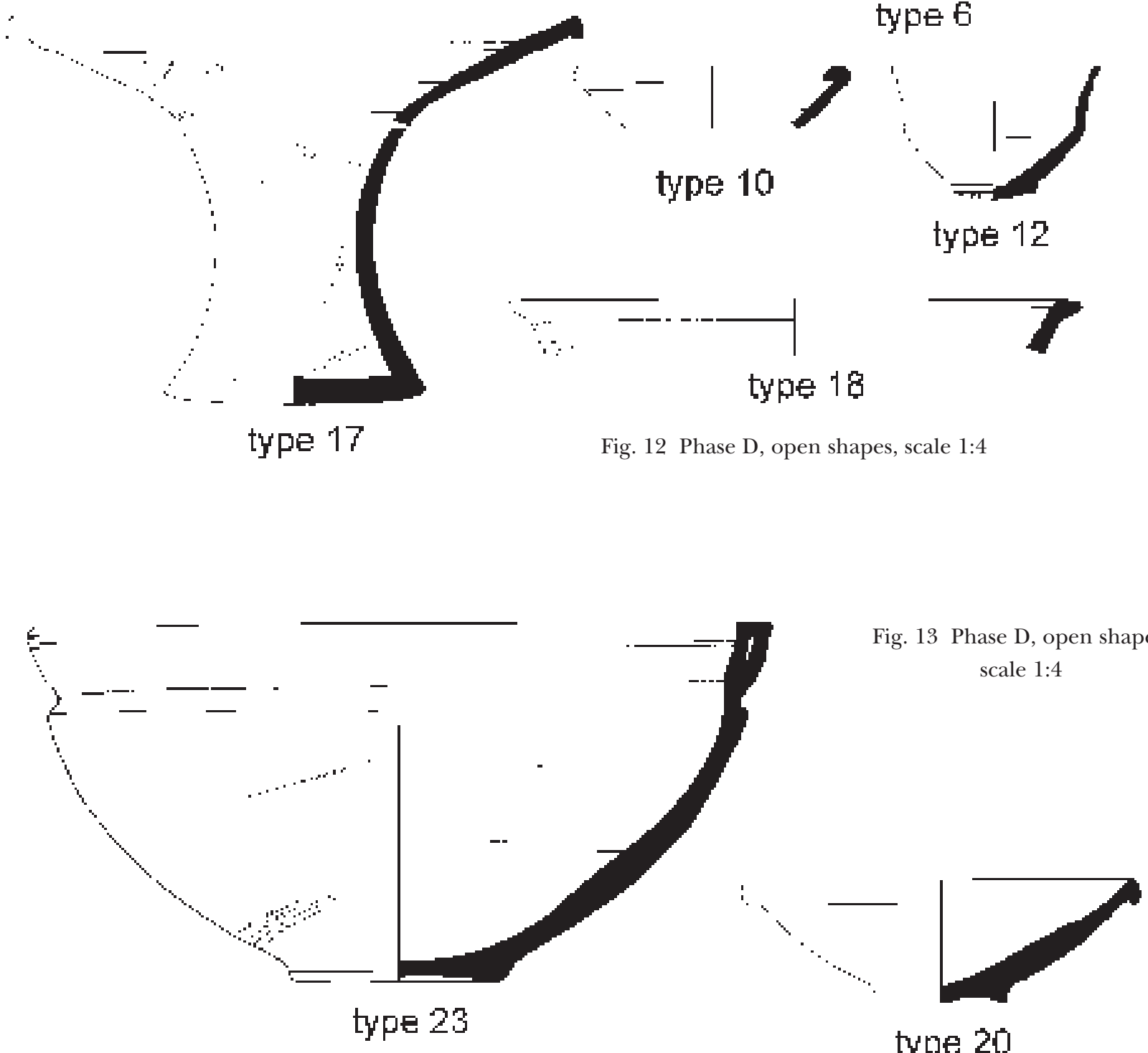

type 20

Fig. 13 Phase D, open shapes, scale 1:4

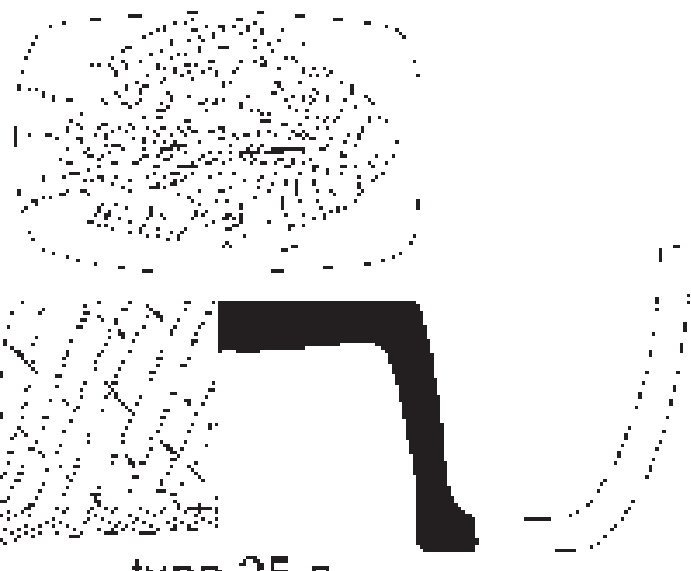

type 25 c

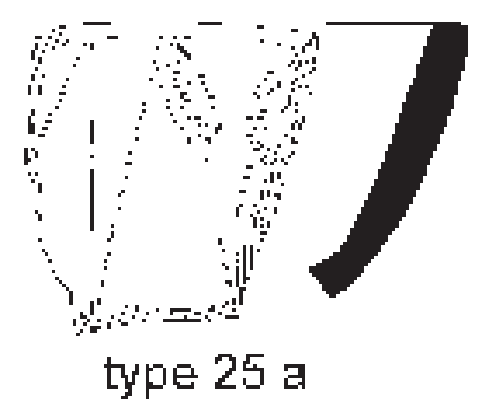


Type 49, small jars with everted rims (Fig. 14), was found in levels corresponding to the advanced $13^{\text {th }}$ Dynasty at Kom Rabica (see above). Perhaps also in this phase the appearance of type 50, small jars with short everted rims (Fig. 14) can be observed. Only a few examples of this type from Tell el-Dabca as well as from Kom Rabica are known to date. ${ }^{179}$

A definitely restricted form is embodied by type 53, bowls with folded rims (Fig. 14) that is only known through two rim fragments from Tell el-Dabca. They were found in str. G/3-1 (=c) and G-F (=c-b/3) respectively. ${ }^{180}$ Types 54, and 55, large and small pots with spouts (Fig. 14) continue in this phase (see above). A possible libation vessel (not illustrated) is represented by type 56 that shows a wide body with wide flat base and a spout. Such vessels made from Marl C are only attested at Memphis/Kom Rabica and Karnak-North. ${ }^{181}$

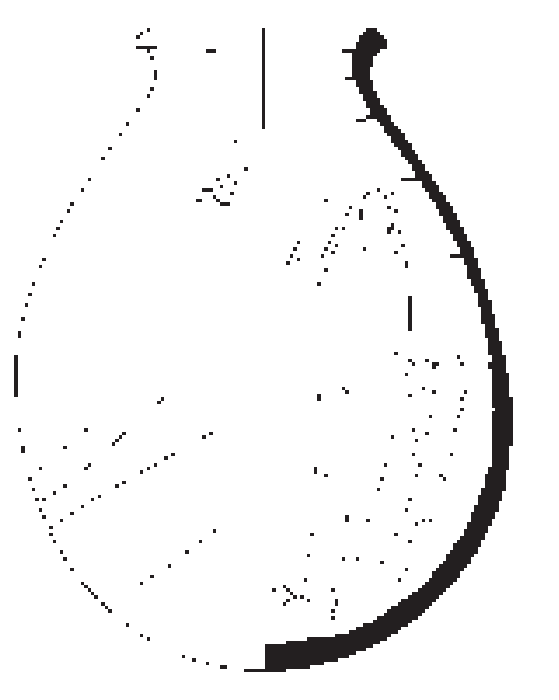

type 36 a

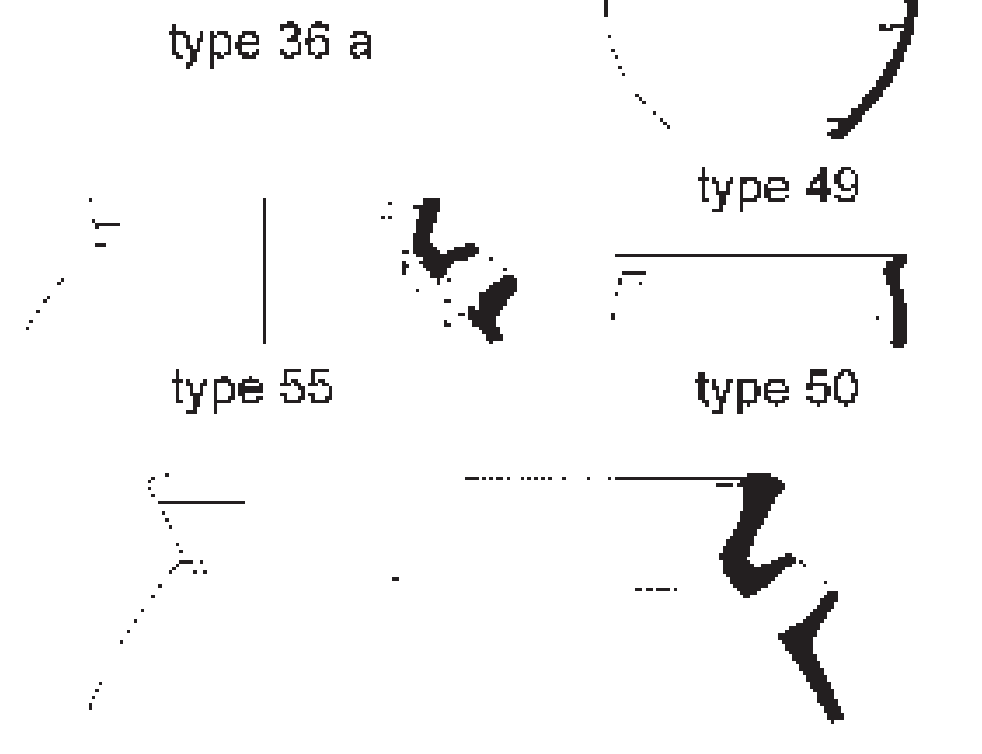

type 54

type 49

type 50
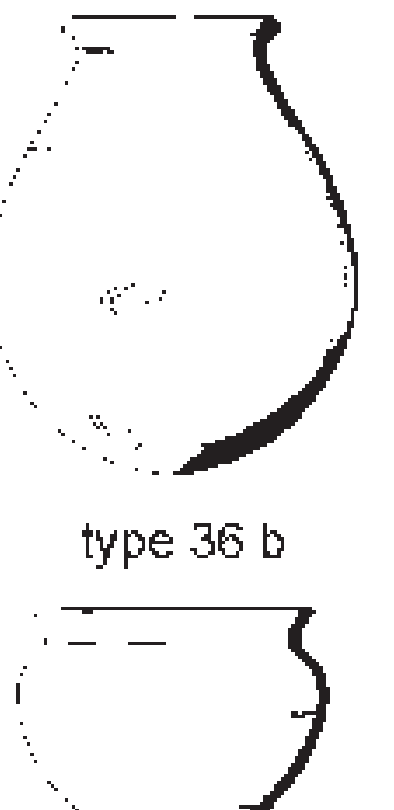

14 Phase D, closed shapes, scale 1:4
${ }^{179}$ B. BADER, TD XIII, 149-151, figs. 41.c, d, e.

${ }^{180}$ B. BADER, TD XIII, 151-2, figs. 41.h, i.

${ }^{181}$ B. BADER, TD XIII, 155, fig. 42.e. Erroneously attrib- uted to "later SIP" by the author. It dates from the middle to the end of the $13^{\text {th }}$ Dynasty (level VIIa), J. Bourriau, personal comm. 
The main types of storage jars are still represented by $57 \mathrm{c}$ and e (see Fig. 9), but as mentioned above the scarcity of vessels with complete profiles prevents us from knowing if there are more variants of shape and size in this period. ${ }^{182}$

Medium-sized to large (vessel height around 25 $\mathrm{cm}$ ) one-handled jugs, type 60 (Fig. 15), seem to possess thin simple rims that are slightly everted. The rim diameter ranges around $10 \mathrm{~cm}$. The handle in section is mostly rounded. Only the one early precursor from the mid $12^{\text {th }}$ Dynasty seems to represent another variant in shape (see above). The bases were made by hand (an extra pad of clay was added for a flat base) and on the wheel (round base, subsequently scraped with a tool), respectively. ${ }^{183}$

Small jars of different forms, collected under the general heading of "model jars" ${ }^{184}$ were found at Dahshur, complex 7, ${ }^{185}$ Kom Rabic ${ }^{186}$ and at Tell el-

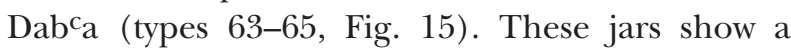
rather bag-shaped body and either a round or flat base. The rims are simple (only rarely folded) and everted. The overall height of these vessels measures in most cases around $10 \mathrm{~cm}$.

Potstands, type 68 (Fig. 15), and Marl C drain pipes are still in use (see above).

\section{Phase E) Later 13 ${ }^{\text {Th }}$ Dynasty}

Phase E corresponds approximately to the latter part of the $13^{\text {th }}$ Dynasty, which is found at Tell elDabca in strata F $(=b / 3)$ and E/3 $(=b / 2)$. Perhaps complex 7 at Dahshur extends up to at least part of that period. Other comparable levels are found at Kom Rabica and presumably at Kahun.

\section{Open Shapes}

In this period open shapes still occur in some variety; namely types 5, small bowls with direct rims, 6, deep bowls, 10, dishes with inner lips, 11, dishes with inverted rims, 17, footed bowls, 23, carinated bowls, 24, carinated bowls with spouts and $25 \mathrm{a}$, fish-dishes with representations of ponds on the inside (all Fig. 16).

New in the repertoire, but nevertheless rare are
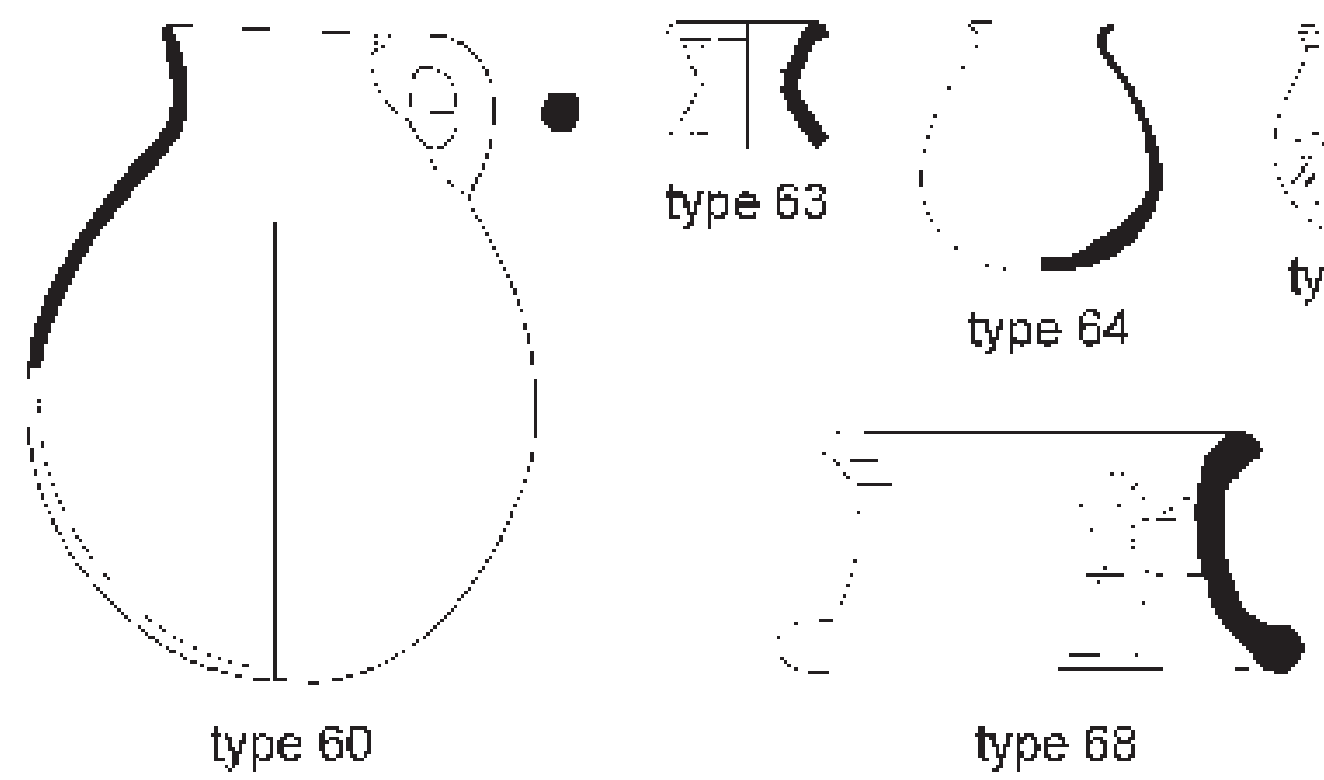

Fig. 15 Phase D, closed shapes and "non-containers", scale 1:4

\footnotetext{
${ }^{182}$ Cf. variants of rim shapes in B. BADER, TD XIII, 161-3, figs. 45.a-d, 46.a. Chart fig. 42.

183 B. BADER, TD XIII, 196-7, figs. 64.g-j, 65.a-d.

184 The restriction that the find spot also identifies a "model" is neglected here for reasons of usefulness.

185 Do. Arnold, MDAIK 38, fig. 11.10. B. BADER, TD XIII, 200-4, types 63, 64, 65 and 66.
}

\footnotetext{
${ }^{186}$ The model jar from context 1549 in B. BADER, TD XIII, 204, Kat.nr. 368.) was mistakenly assigned to the late SIP by the author, but it dates to the mid to later $13^{\text {th }}$ Dynasty (level VIIb), J. Bourriau, pers. comm.
} 

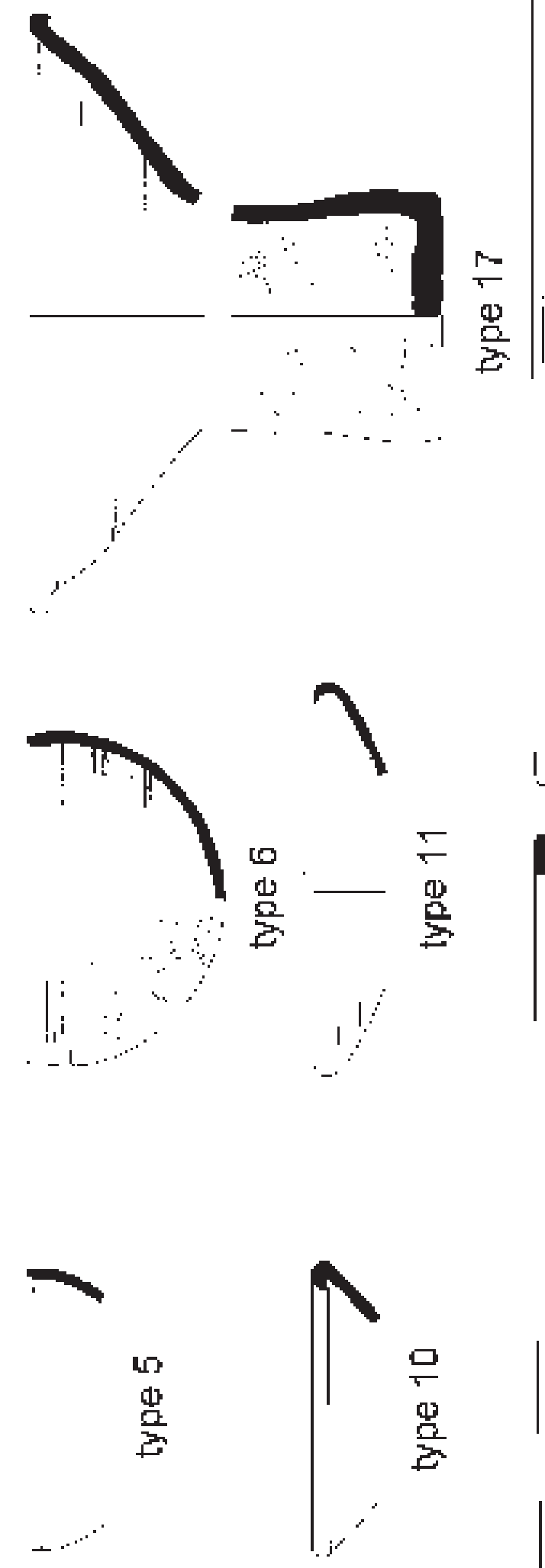

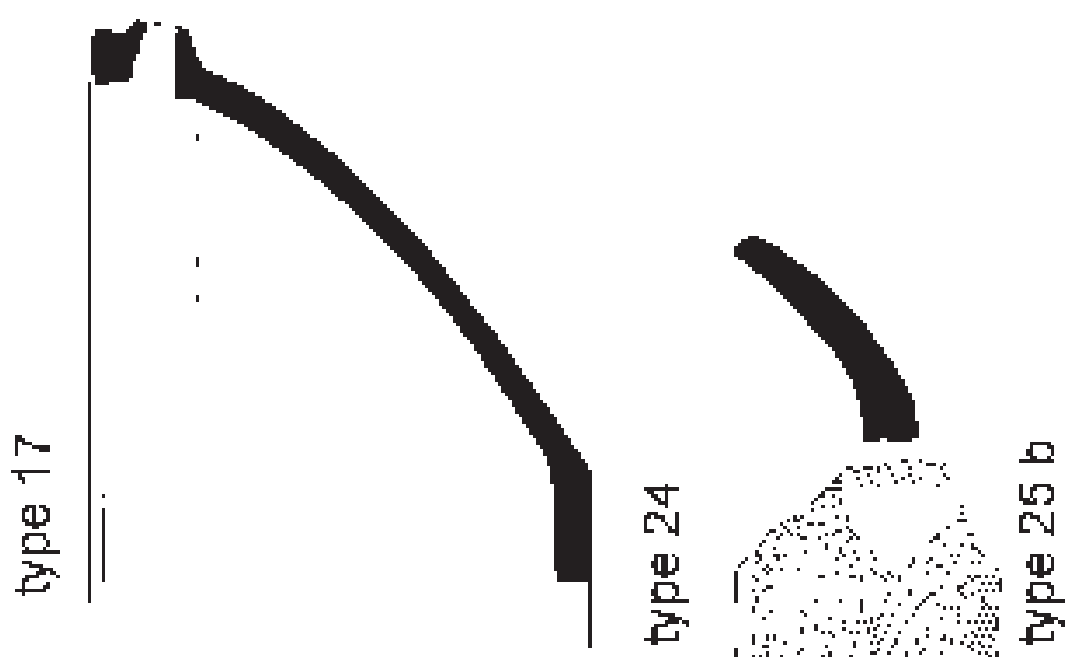

15

si

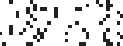

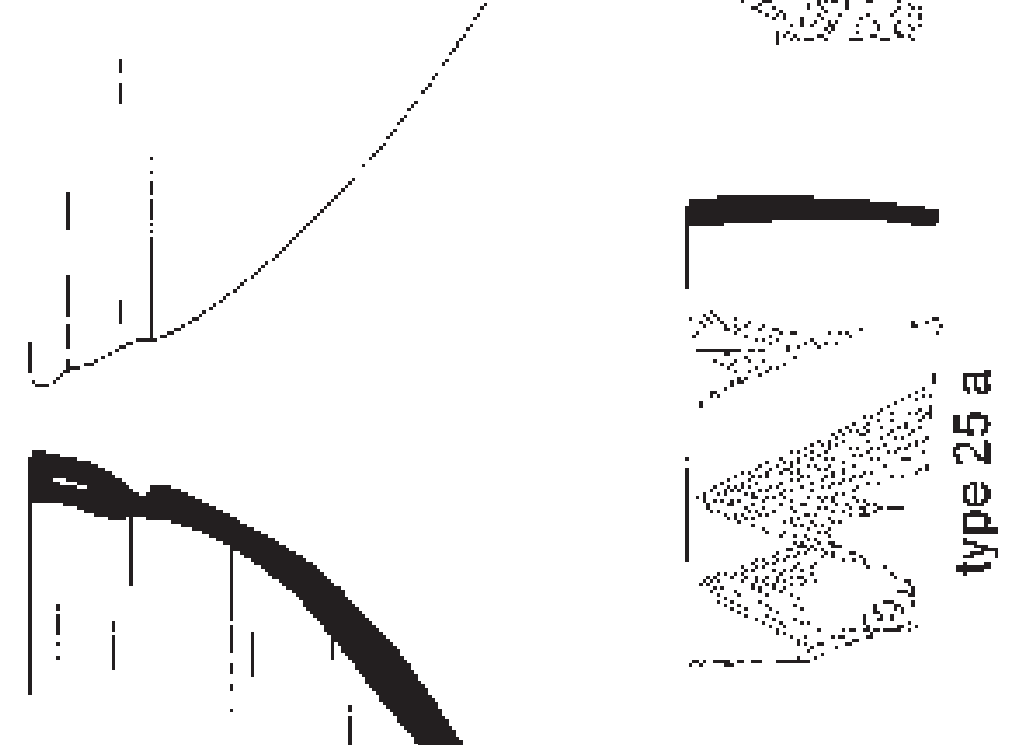

$w$
0
$z$ 
type 3, large dishes with straight sides (which is only known through rim sherds) type 15, large bowls with flat bases, type $25 \mathrm{~b}$, "fish dishes" with representations of fish on the inside and type $25 \mathrm{~d}$, vessels similar in shape to fish dishes, but without incisions. ${ }^{187}$

Specimens of type $25 \mathrm{~b}$ (Fig. 16), oval dishes with incised depictions of fish are found quite frequently. Unfortunately so far only a few examples came from dated contexts, namely Tell el-Dabca strata $\mathrm{E} / 3-2(\mathrm{~b} / 2-1)$ and $\mathrm{E} / 1(=\mathrm{b} / 1)$. This class finds ready parallels at Kom $\mathrm{Rabi}^{\mathrm{C}} \mathrm{a}$, that appear in all levels from the later $13^{\text {th }}$ Dynasty to the end of the Second Intermediate Period. ${ }^{188}$ Somehow related to this type seems to be an oval dish, type $25 \mathrm{~d}$. Known only from rim fragments these dishes, which do not seem to have been incised, are characterised by rows of pierced holes just under the rim. Because
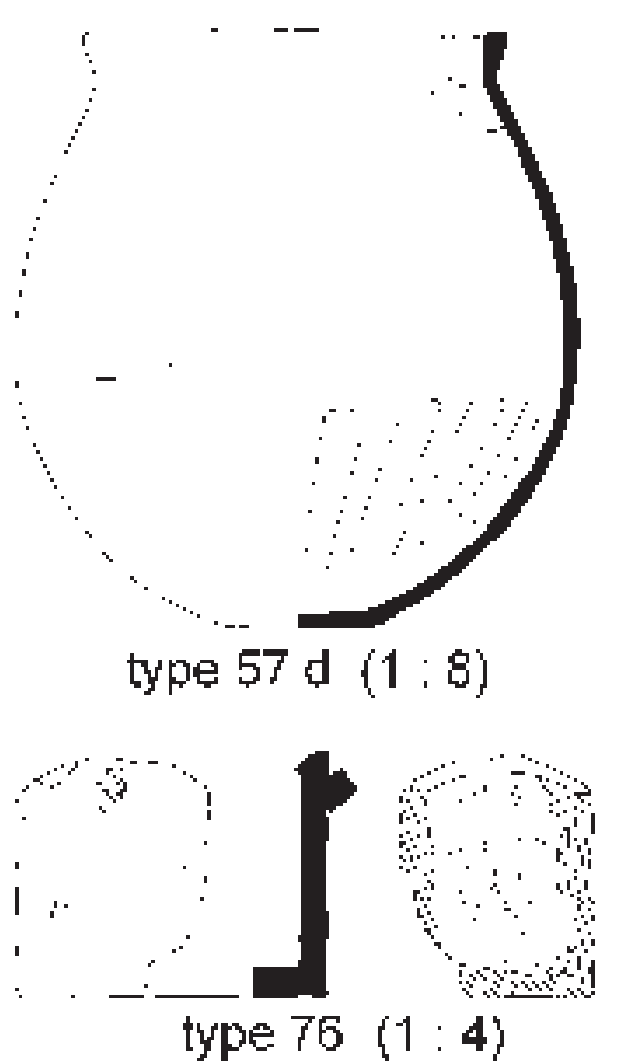

Fig. 17 Phase E, closed shapes and "non-containers"

\footnotetext{
${ }^{187}$ Because of their rare appearance types 3, 15 and $25 \mathrm{~d}$ are not illustrated. Cf. B. BADER, TD XIII, 47, figs. 4.h, i; fig. 6.g, 98-9, figs. 20.g, h.

${ }^{188}$ Levels VIe to VIa, J. Bourriau, pers. comm.

${ }^{189}$ Cf. B. BADER, TD XIII, 98-9, figs. 20.g, h.

${ }^{190}$ B. BADER, TD XIII, 224, fig. 70.h
}

they are also handmade, they were assigned to the larger group $25 .^{189}$

\section{Closed shapes}

Almost all of the closed vessel types current in this phase have already made their appearance earlier. Still present in the repertoire are types $36 \mathrm{a}$ and $\mathrm{b}$, medium-sized jars, 46, jars with corrugated necks, 50, small jars with short everted rims, 55 and 54, large and small pots with spouts, 60, one-handled jugs, 63-66 several types of small or "model" jars, 68, potstands and 73, drain pipes (see Figs. 13 and 14).

The only additional vessel types are the storage jar, type $57 \mathrm{~d}$ (Fig. 17), that occurs side by side with the already known type 57 e (see Fig. 9) and the somewhat mysterious type $76^{190}$ (Fig. 17) that seems to be part of a casket of some sort. It is rectangular or even square with a knob on its side and seems to have been open on top, perhaps to be closed with cloth or leather and string. The rat trap from Kahun suggests that it was not entirely uncommon to produce different objects from Marl C clay. ${ }^{191}$

Storage jars, type $57 \mathrm{~d}$ (Fig. 17), show a rather squat shape with a small flattened base. The manufacturing technique is the same as is typical for vessel family 57: body handmade with the rim turned on the wheel or a turntable. Only 3 examples with complete profile survived in Tell el-Dabca strata $\mathrm{F}$ (= $\mathrm{b} / 3)$ to $\mathrm{E} / 1(=\mathrm{b} / 1)$. The distinction between types $57 \mathrm{~d}$ and e on the basis of rim fragments alone (Figs. $9,17)$ is not possible as they look quite similar to each other. A clue may perhaps be gained by means of the rim diameter. The diameters of type $57 \mathrm{~d}$ range between 31.5 and $34.5 \mathrm{~cm}$ whereas rims of type 57 e generally measure less than $30 \mathrm{~cm}^{192}$

\section{Phase F) Late Second Intermediate Period $\left(13^{\mathrm{TH}} / 15^{\mathrm{TH}}\right.$ DyNASTY) TO EARLY $18^{\mathrm{TH}}$ DYNASTY}

While an indigenous material culture derived from Middle Bronze Age Palestine was established in the Eastern Delta during this phase, ${ }^{193}$ hardly any features of it can be found as little to the south as the old town of Memphis/Kom Rabica.

\footnotetext{
191 D. C. Drummond, R. M. and J. J. Janssen, An Ancient Egyptian Rat Trap, MDAIK 46 (1990), 91-8.

192 B. BADER, TD XIII, 163-78.

${ }^{193}$ Cf. M. BIETAK, Tell el-Dabc $a$ V, Vienna 1991, passim. D. A. Aston, Tell el-Dabca XII, A Corpus of Late Middle Kingdom and Second Intermediate Period Pottery, in press, vol. 2, passim.
} 
The development of pottery styles had obviously, by this time, arrived at a crossroads and regional distinctions were becoming quite marked. Perhaps it is feasible to expect even more than these two local styles all over Egypt in this still largely enigmatic late and latest Second Intermediate Period. ${ }^{194}$

At Tell el-Dabca Phase $\mathrm{F}$ is equated with strata E/2-D/2 (= b/1-a/2), the Hyksos Period, whereas at Memphis/Kom Rabica it seems more sensible to call Phase F "developed 13 th Dynasty" 195 because the style of the pottery shows continuity with the style in use in the late Middle Kingdom in the Memphis-Fayoum region and is quite different from that found in the Delta. Similarly the same chronological period may be identified as the $17^{\text {th }}$ Dynasty at Thebes or Elephantine. ${ }^{196}$ The comparative synchronisation between different parts of Egypt at this time is unclear, because current research on this period is still not advanced enough for secure chronological conclusions. There are many blank spaces all over Egypt, where little or no data is available, especially outside of the large urban centres such as Avaris, Memphis, Abydos, Thebes and Elephantine, with the exception of Deir el-Ballas. ${ }^{197}$

\section{Open shapes}

At Tell el-Dabca it is very noticeable that by stratum $\mathrm{D} / 2$ most of the open shapes are no longer present in the repertoire, except for some remote examples of types 17 , footed bowls, 20, bowls with simple contours, rolled rims and flat bases and 23, carinated bowls ${ }^{198}$ (all Fig. 18).

At Kom Rabic a the variety and frequency of open Marl C vessels is larger ${ }^{199}$ than in the Delta. Type 5,

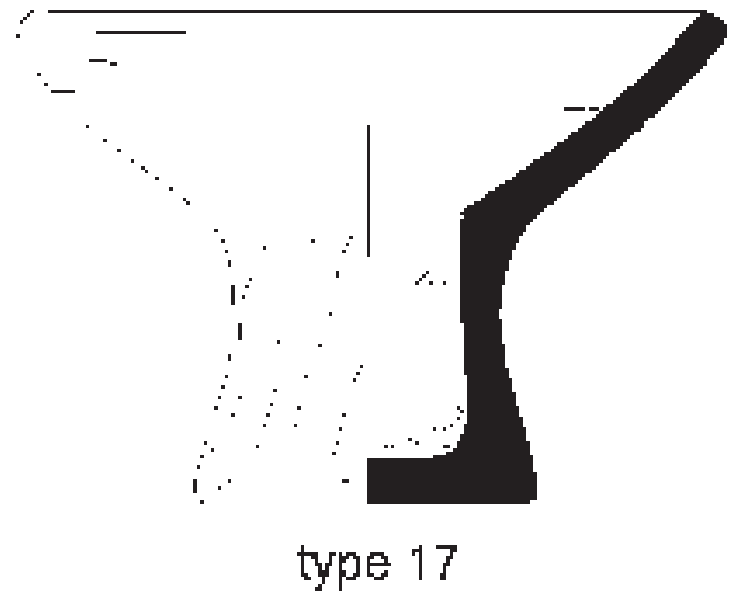

Fig. 18 Phase F, open shapes, scale $1: 4$
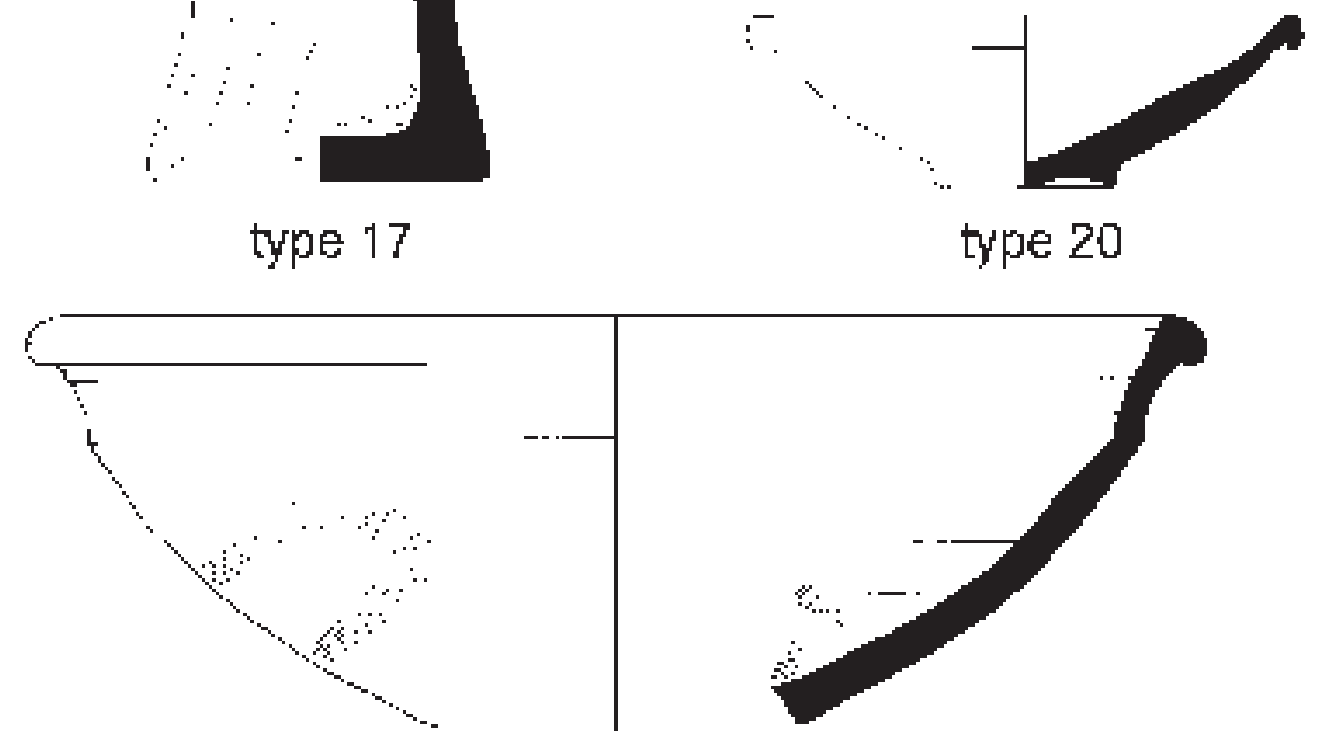

${ }^{194}$ J. Bourriau, Beyond Avaris. The Second Intermediate Period in Egypt Outside the Eastern Delta, in: E. D. Oren (ed.), The Hyksos - New Historical and Archaeological Perspectives, Philadelphia 1997, 159-182.

195 J. Bourriau, K. O. Eriksson, A Late Minoan Sherd from an Early $18^{\text {th }}$ Dynasty Context at Kom Rabica, Memphis, in: J. Phillips (ed.), Ancient Egypt, The Aegean and the Near East: Studies in Honour of Martha Rhoads Bell, San Antonio 1998, 102-3.

${ }^{196}$ Perhaps to be connected with „Bauschicht“ 11 that is currently dated to the $17^{\text {th }}$ Dynasty. C. v. Pilgrim, Elephantine XVIII, 15.

197 J. Bourriau, The Pottery, in: P. Lacovara, Deir el Ballas. Preliminary Report on the Deir el Ballas Expedition, 1980-1986, Winona Lake 1990, 15-22.

198 B. BADER, TD XIII, 60-7, 68-70, 72-9.

${ }^{199} \mathrm{~J}$. Bourriau, pers. comm. Not all types will be shown here. 
small bowls with direct rims (Fig. 19), still occurs in the later part of the Second Intermediate Period. Type 14, thick-walled bowls with direct rims and flat bases (Fig. 19) is represented by a single example, dating to the same time. Large bowls with flat bases, type 15 (Fig. 19), are hitherto unknown made of Marl C outside of Kom Rabica/Memphis. ${ }^{200}$ The same holds true for slightly incurved bowls with ring bases, type 16 (Fig. $19)$, which are found in a variety of shapes and sizes.

As far as is known type 16 occurs only in levels dated to the later Second Intermediate Period with possible extensions into the early New Kingdom. ${ }^{201}$ Rim fragments that may be attributed to type 17 , footed bowls (see Figs. 12 and 15) also occur at this time,

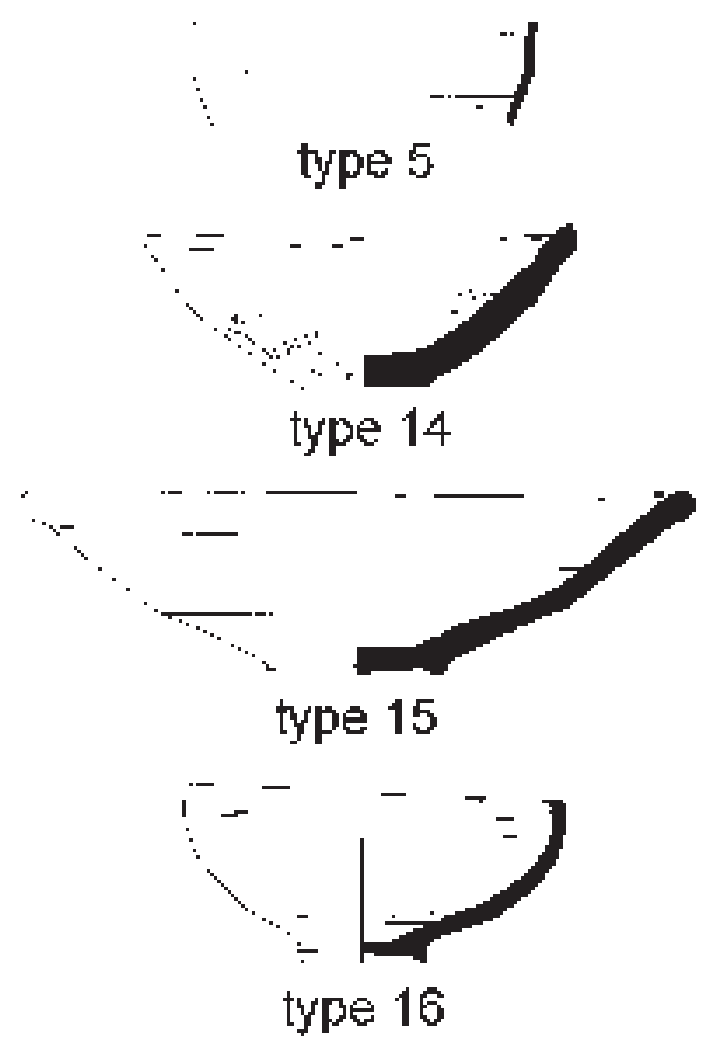

Fig. 19 Phase F, open shapes, scale 1:4

${ }^{200}$ B. BADER, TD XIII, 59, figs. 6.g, h. One rim fragment comes from a level dating ca. mid to end of $13^{\text {th }}$ Dynasty.

${ }^{201} \mathrm{~J}$. Bourriau, pers. comm. Some rim fragments that may attributed to that type occur a little earlier. B. BADER, TD XIII, 57-60.

202 J. Bourriau, pers. comm., B. BADER, TD XIII, 68, figs. 10.a-b.

${ }^{203}$ B. BADER, TD XIII, 70, figs. 10.h, 11.a.

${ }^{204}$ J. Bourriau, pers. comm., cf. B. BADER, TD XIII, 72-6. as do rim fragments of type 19, slightly restricted bowls with rolled rims. ${ }^{202}$ Type 20, bowls with simple contours, rolled rims and flat or ring bases (Fig. 18) continue. A seemingly late type is 21 , bowls with wavy line incisions inside and outside. No complete example has been found, so that its overall shape cannot be postulated with any certainty. A straight-walled bowl is possible. ${ }^{203}$ Of Type 23, carinated bowls (Fig. 18) and 25 b, fish-dishes with representations of fish in the middle (Fig. 16) several examples survive into the late Second Intermediate Period. ${ }^{204} \mathrm{~A}$ singular piece made of marl $\mathrm{C}$ of this period is type 26 , spinning bowls. ${ }^{205}$

\section{Closed shapes}

In the beginning of this phase (at Tell el-Dabca str. $\mathrm{E} / 2-\mathrm{D} / 3$ ) some examples of types $36 \mathrm{a}$ and $\mathrm{b}$, medium-sized jars, type 46, jars with corrugated necks, type 64 , round-based "model" jars and type 68, potstands still make their appearance although they are rare in the Delta (all Fig. 20).

Storage jars of type $57 \mathrm{~d}$ (see Fig. 17) and e are still found in the beginning of Phase F), while type $57 \mathrm{f}$ (Fig. 21), which is only known through one complete example from Tell el-Dabca str. E/1 (= $\mathrm{b} / 1)$, exists only at that time.

Up to stratum D/2 only types 37 , medium-sized jars with incised linear decoration and flat bases ${ }^{206}$ and storage jars of types $57 \mathrm{~g}$ and $57 \mathrm{i}^{207}$ (Fig. 21) survive at Tell el-Dabca. The shape of type 57 i continues perhaps into the early $18^{\text {th }}$ Dynasty, since similar rims appear in early $18^{\text {th }}$ Dynasty strata, but made from a different marl clay. It is unclear, however, whether we are confronted with residual sherds or if they are contemporary with the levels in which they were found. ${ }^{208}$

The only contemporary site of which we have some information is, to date, Memphis/Kom Rabi$\mathrm{c}_{\mathrm{a}}$. There many more different types of Marl $\mathrm{C}$ pottery were unearthed in levels that are presumed to date to the very end of the Second Intermediate Period and perhaps even into the earliest $18^{\text {th }}$

${ }^{205}$ B. BADER, TD XIII, 99-100.

${ }^{206}$ B. BADER, TD XIII, 120, fig. 27.i.

${ }^{207}$ Hitherto only rims or complete vessels without description of the clay can be cited as parallels. Cf. B. BADER, TD XIII, 179. Such rims consist mainly of a very sandy variant of Marl C2. Cf. B. BADER, TD XIII, 40.

${ }^{208}$ Cf. discussion of possible reconstruction and parallels in B. BADER, TD XIII, 185-7. Marl F, I. HeIn, Erste Beobachtungen zur Keramik aus Ezbet Helmi, $\ddot{A} \mathcal{E} L 4$, 40, figs. 11.g-h. 
Dynasty. ${ }^{209}$ They are mostly represented by a variety of jar rims; $;{ }^{210}$ types 32 , direct, out-turned rims, type 34 a, necked jars with folded rims, type 45, upright, folded rims and type 46, jars with corrugated necks (see Fig. 20) as well as by some rims of large storage jars that can be attributed to type 57 e (Fig. 21). A few jar types preserved a complete profile like type 38 , bagshaped jars with folded rims and short necks, type 51, squat jars with overhanging lips, type 52, globular jars with necks and folded rims ${ }^{211}$ (all Fig. 22). The base of what could be reconstructed as a "beaker jar" was found in a level that can be dated to this period. ${ }^{212}$ To the class of "non-containers" belong types 68 , potstands (see Fig. 20) and type 71, lids. ${ }^{213}$

It is important to note that in the published pottery corpus from Elephantine of the late Second Intermediate Period no Marl C pottery seems to occur at this time.
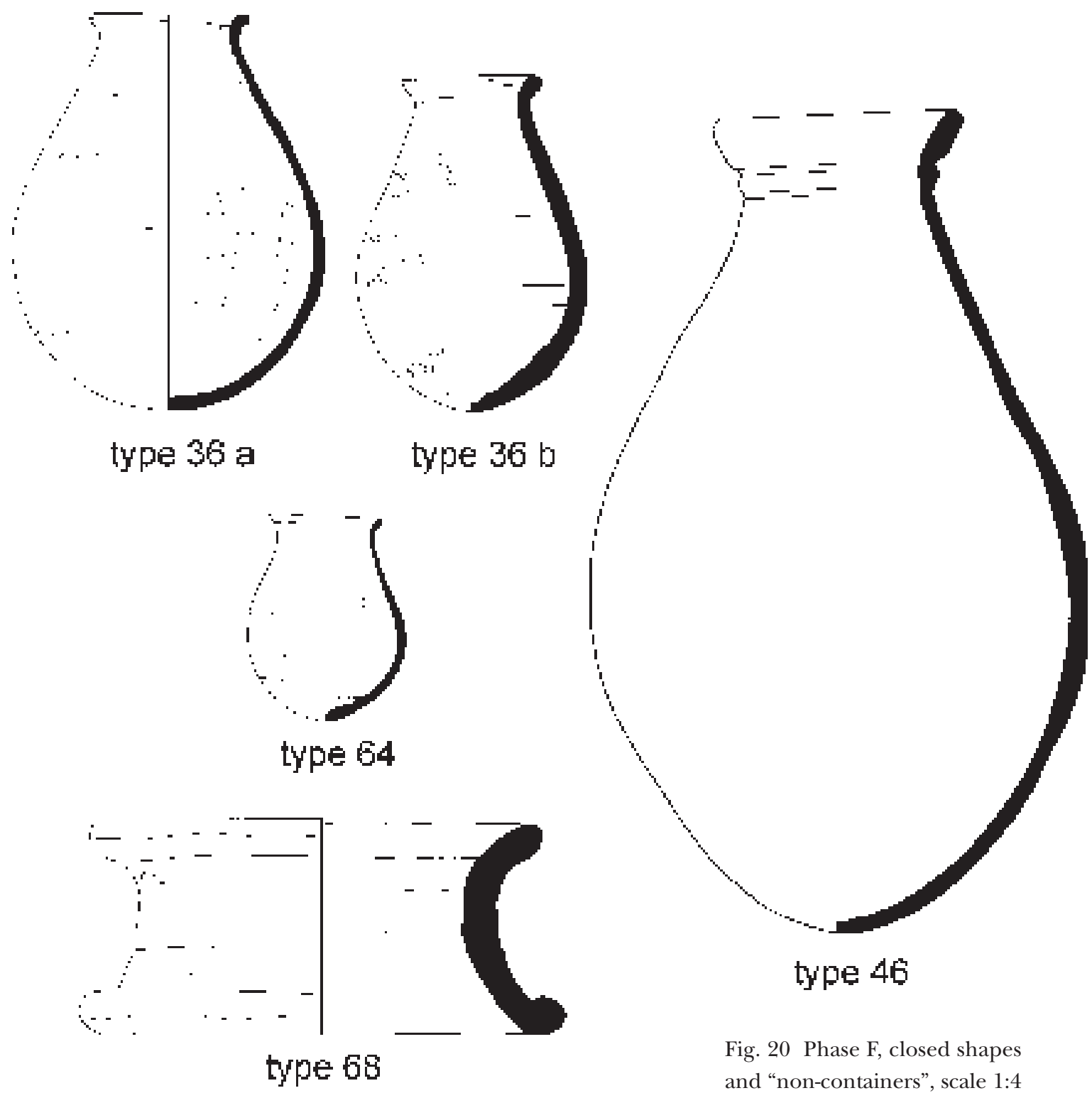

Fig. 20 Phase F, closed shapes and "non-containers", scale 1:4

\footnotetext{
${ }^{209}$ J. Bourriau, pers. comm.

210 Only a selection is presented here. B. BADER, TD XIII, 104, fig. 22.b; 107, fig. 22.j; 127, fig. 29.c; 177, fig., 53.c.
}

\footnotetext{
211 B. BADER, TD XIII, 122, fig. 28.a, 151, figs. 41. f-g.

${ }^{212}$ B. BADER, TD XIII, 205, fig. 66.o.

${ }^{213}$ B. BADER, TD XIII, 217-8, fig. 70.e.
} 
In Kom Rabica in level V, which is currently equated with the transition from the Second Intermediate Period to the early $18^{\text {th }}$ Dynasty, ${ }^{214}$ the following types of open forms, amongst others, were still found: type 4, small dishes, type 7, bowls with inverted rims and incised lines, type 8, straight-walled bowls, type 16, slightly incurved bowls with ring bases (see Fig. 18) and type 19, slightly restricted bowls with rolled rims. ${ }^{215}$ The closed vessels are, amongst others, represented by jar rims of type 34, folded rims, type 34 a, necked jars with folded rims, type 43, folded and trimmed rims of jars and type 50, small jars with short everted rims (see Fig. 13). ${ }^{216}$

It is possible that these mainly fragmentary sherds may be residual. By level IV Marl C has disappeared even in Memphis. ${ }^{217}$

The main questions that have been asked in connection with Marl C-pottery, namely "Were these vessels mainly used for trade and transport?" and "If so, which commodities have been transported?", can still not be answered in full. At least, we now have a clearer picture in some respects. As for the first question, the reply must be, "at least partly". On the one hand the fabric, that is thought to be from the Memphis-Fayoum region, ${ }^{218}$ has been found at such remote places as Qasr-el-Sagha, Serabit el-Khadim, the Northern Sinai and at Askut in Nubia. This fact certainly suggests trade and distribution by some kind of centralised state system. On the other hand not only closed vessels that would have been used to transport commodities of any kind have been found at those sites, but open shapes as well. Work at Kom Rabica showed that there are many more variants of open shapes than hitherto thought and this indicates that the fabric was thought suitable not only for storage and transport, but also for very special pottery classes like fish dishes, drains, rat traps and lids.

A partial answer to the second question can also

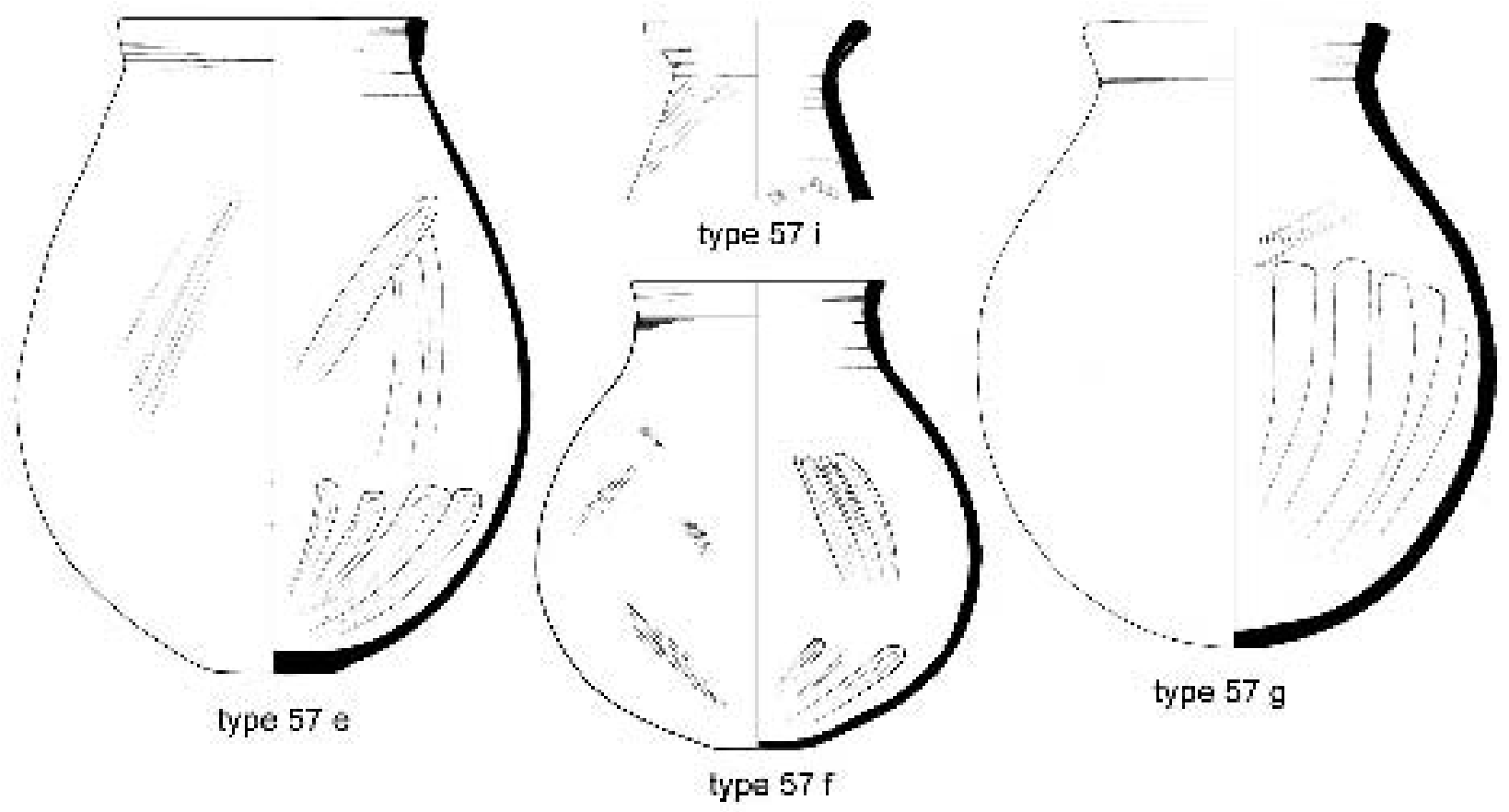

Fig. 21 Phase F, closed shapes, scale 1:4

\footnotetext{
${ }^{214}$ See site report D. G. Jefrreys, L. L. Giddy, Memphis 1986, 1987, JEA 74 (1988), 17-19.

${ }^{215}$ B. BADER, TD XIII, 47-8, fig. 3.j; 51-2, figs. 4.1-m; 68, fig. 10.b.

${ }^{216}$ B. BADER, TD XIII, 105-6, figs. 22.e-f, k.

${ }^{217}$ J. Bourriau, K. O. Eriksson, Late Minoan Sherd, 107-8.
}

Unfortunately there are no other reliable sequences that reach that far.

${ }^{218}$ Because the fabric appears at sites in Upper Egypt, apparently quite frequently, the last certainty to the question of origin will only be resolved by the discovery and testing of mining areas or the finding of kiln sites. 
be given, as some inscribed vessels and pictorial representations have been found, which indicate that shapes such as type 46, jars with corrugated necks were used for water and wine. ${ }^{219}$ Examples of type 57 also bore dockets indicating they contained oil or myrrh. ${ }^{220}$ However, this does not mean that these vessels may not have contained several different commodities in their life-time. Analyses of contents, e.g. at Lisht, have shown that building materials were also stored in them. ${ }^{221}$

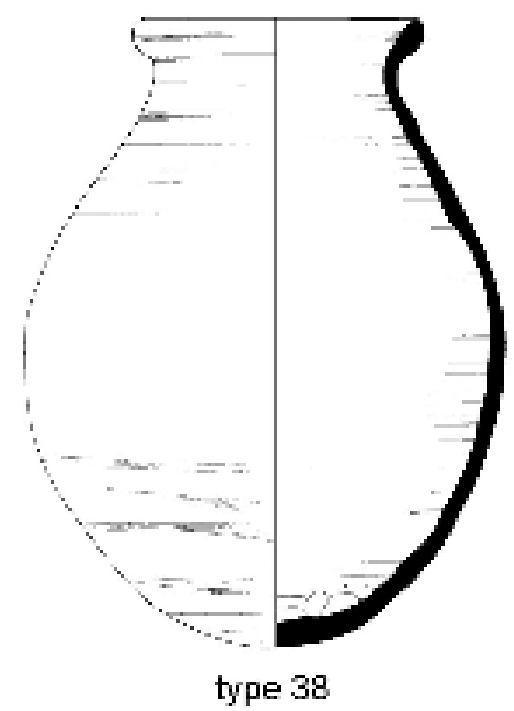

Fig. 22 Phase F, closed shapes, scale 1:4
Another benefit that may be gained by studying Marl C-pottery is the possibility of correlating the stratigraphies of different sites, especially Lower Egypt and the Memphis-Fayoum region. It has to be noted, though, that most of the types are rather longlived and perhaps provide too few links by themselves to date any one level. However, it is hoped that some insight into the larger picture of the development and importance of this pottery fabric is given by the corpus presented here.

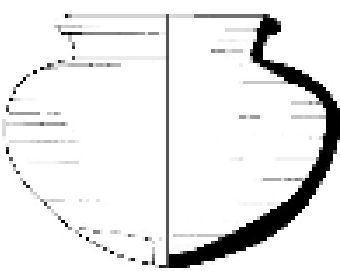

type 51

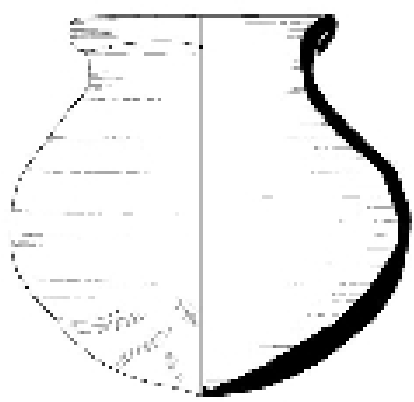

type 52
219 Do. ARnOld, Wüstentone, 185-6, footnote 97. H. O. Lange, H. SchäFer, Grab- und Denksteine des Mittleren Reiches, Catalogue général des antiquités égyptiennes du musée du Caire, Berlin 1902, 349-352, Nr. 20722.
${ }^{220}$ S. ALLEN, Queens' Ware, 45-46.

221 Natron - Engelbach, GunN, Harageh, 3, 10, 32. Do. ARNOLD, Senwosret I, 109-10. 